Puede citar este artículo como:

MAS GALVAÑ, Cayetano, «Devociones, conflictividad y clima. Los santuarios de Nuestra Señora de las Virtudes (Villena) y San Cayetano (Crevillent) durante la Edad Moderna», Revista de Historia Moderna. Anales de la Universidad de Alicante, n. ${ }^{\circ} 35$ (2017), pp. 254-307, DOI: 10.14198/RHM2017.35.08.

\title{
DEVOCIONES, CONFLICTIVIDAD Y CLIMA. LOS SANTUARIOS DE NUESTRA SEÑORA DE LAS VIRTUDES (VILLENA) Y SAN CAYETANO (CREVILLENT) DURANTE LA EDAD MODERNA*
}

\author{
CaYetano Mas GaLVAÑ \\ Universidad de Alicante \\ cayetano.mas@ua.es
}

\section{Resumen}

En el marco de procesos más amplios o simultáneos (confesionalización, conventualización) la fundación de ermitas y santuarios adquirió una gran extensión durante la Edad Moderna en España. La trayectoria de estos centros espirituales a menudo fue acompañada de una variada conflictividad, desde litigios judiciales por el patronazgo hasta episodios violentos y tumultos populares. Además, dado el papel como intercesores que se asignaba a los santos y vírgenes venerados en dichos santuarios, las coyunturas climáticas adversas de la Pequeña Edad del Hielo aparecen asociadas a parte de esta conflictividad. Sobre la base de una variada documentación original, el presente trabajo tiene por objeto el estudio comparativo, combinando dichos factores, de dos casos de santuarios relevantes situados en un área próxima del Mediterráneo español (diócesis de Cartagena y Orihuela). Por encima de las lógicas similitudes, los resultados evidencian la necesidad de atender a los contextos locales, tanto en la explicación de la conflictividad como en la interpretación de conocidos proxy-data climáticos (en particular, las rogativas pro pluvia).

Palabras clave: Santuarios, conflictividad, clima, España, siglos XVI-XVIII, Pequeña Edad del Hielo

\footnotetext{
* Este trabajo se ha elaborado en el marco del proyecto HAR2013-44972-P, incluido en el Programa Estatal de Fomento de la Investigación Científica y Técnica de Excelencia promovido por el MINECO (Ministerio de Economía y Competitividad del Gobierno de España).
} 
Devociones, conflictividad y clima. Los santuarios de Nuestra Señora de las Virtudes (Villena) y San Cayetano (Crevillent) durante la Edad Moderna

\begin{abstract}
Devotions, Conflicts and Climate. The Shrines of Nuestra Señora de las Virtudes (Villena) and San Cayetano (Crevillent) during the Early Modern Period

In the context of more extensive or simultaneous processes (confesionalization, conventualization) the foundation of hermitages and shrines acquired a great extension during the Early Modern Age in Spain. The trajectory of these spiritual centers was often accompanied by a variety of conflicts, from lawsuits for patronage to violent episodes and popular riots. In addition, because the role as intercessors assigned to the saints and virgins worshiped in these shrines, the adverse climatic conjunctures of the Little Ice Age are associated with part of these conflicts. This paper aims at comparative study, combining both factors (conflicts and climate) of two cases of relevant shrines located in an area of the Spanish Mediterranean (Dioceses of Cartagena and Orihuela). Beyond the logical similarities, the results show the need to attend to the local contexts, both in explaining the conflict and in its incidence in the interpretation of usual climatic proxy-data (in particular pro-pluvia prayers).
\end{abstract}

Keywords: Shrines, conflicts, climate, Spain, XVI-XVIII centuries, Little Ice Age

\title{
1. Introducción
}

Si durante la Edad Moderna asistimos a la configuración de una España conventual ${ }^{1}$, también el proceso de fundación de ermitas y santuarios adquirió una extensión y profundidad innegables. Para confirmarlo, a modo de ejemplo, basta consultar un reciente catálogo de las ermitas de la actual provincia de Alicante: de las más de 500 inventariadas (sumando las hoy existentes y las documentadas), un $70 \%$ son de época medieval y, sobre todo, moderna ${ }^{2}$.

Dada la escasez y naturaleza de las fuentes disponibles (muy contaminadas por elementos apologético-piadosos), a menudo se hace difícil profundizar en el estudio de casos particulares. Sin embargo, cuando por diversas razones una ermita adquiere una mayor dimensión, fama, y perduración, hasta el punto de poder calificarla como santuario, su traza en la documentación histórica se hace claramente presente. No solo por la entidad de la institución, sino porque tal relevancia suele ir asociada a una amplia gama de

1. ATIENZA, 2008: 13.

2. CANDELAS, 2004. MONTESINOS, 1795.

Revista de Historia Moderna, n. ${ }^{\circ} 35$ (2017) (pp. 254-307) | ISSN-e: 1989-9823 | ISSN: 0212-5862 
Devociones, conflictividad y clima. Los santuarios de Nuestra Señora de las Virtudes (Villena) y San Cayetano (Crevillent) durante la Edad Moderna

conflictos, tan habituales en una sociedad como la Moderna ${ }^{3}$. Por supuesto, esta conflictividad no se presenta aislada ni desvinculada de las estructuras de poder y de las relaciones sociales existentes en cada contexto. Pero en no pocos casos, y en una economía tan expuesta a los factores naturales como aquella, el telón de fondo o el detonante que desencadena dichos conflictos viene dado por las consecuencias de coyunturas climáticas adversas, en las que tan pródiga fue la Pequeña Edad del Hielo ${ }^{4}$.

Desde este enfoque, en el que combinamos conflictividad y factores climáticos, en el presente trabajo analizamos y comparamos dos casos de santuarios situados en un área próxima (de hecho, hoy forman parte de la provincia de Alicante), fundados durante la Edad Moderna: el de Nuestra Señora de las Virtudes (Villena) y el de San Cayetano (Crevillent). Los hitos básicos de la trayectoria del primero de ellos (en territorio de realengo perteneciente entonces a Castilla y a la diócesis de Cartagena) son conocidos, por lo común merced a estudios de óptica local; ello ha permitido efectuar una revisión de la documentación original desde la aproximación que proponemos 5 . En cuanto al segundo de estos santuarios (sometido a jurisdicción señorial, enclavado en el sur valenciano y en la diócesis de Orihuela), su historia era mucho menos conocida y se ha trazado aquí prácticamente ex novo a partir de los fondos archivísticos disponibles ${ }^{6}$.

3. Sobre el modo en que eran entendidos estos conceptos en la propia Modernidad, vid. IGLESIAS RODRÍGUEZ: 2016.

4. Alberola, 2014.

5. La casi totalidad de la documentación procede del Archivo Histórico Municipal de Villena, y particularmente de sus actas capitulares (en adelante, AHMV, AACC). Esta serie documental se inicia en 1564. En los fondos de legajos del mismo archivo existen documentos anteriores relacionados con el santuario de Las Virtudes; los más significativos fueron mandados compilar e imprimir por el ayuntamiento como consecuencia del pleito de 1756-1757 (Diferentes instrumentos... [1768]. AHMV, 15/1, 15/2).

6. Nos centraremos en la segunda época de este santuario (1792-1826), en extremo conflictiva (que ha sido objeto de estudio de nuestra comunicación presentada a la XIV Reunión Científica de la FEHM celebrada en Zaragoza en 2016, en curso de publicación). La principal fuente son los más de dos mil folios del pleito existente en el Archivo Histórico Nacional, Consejos, 23.187, El cura y clero de la Iglesia Parroquial de la villa de Crevillente con José y Celedonio Ardid [...] sobre si debe conservarse, o no la imagen de San Cayetano en la Iglesia Parroquial de dicha villa, año 1815 (en adelante, AHN, Consejos, 23.187, El cura y clero...); y algunas fuentes locales, en particular el archivo parroquial de Nuestra Señora de Belén de Crevillent (APBC). La sección Nobleza del mismo AHN 
Devociones, conflictividad y clima. Los santuarios de Nuestra Señora de las Virtudes (Villena) y San Cayetano (Crevillent) durante la Edad Moderna

\section{El santuario de Nuestra Señora de las Virtudes (Villena)}

Probablemente erigido como ermita en la última década del siglo $\mathrm{XV}^{7}$, a causa de un episodio de pestilencia insuficientemente documentado ${ }^{8}$, la trayectoria de este santuario -situado a una legua extramuros de Villena- está íntimamente ligada al proceso político sufrido por su municipio: tras rebelarse abiertamente contra el titular del marquesado en 1476, la entonces villa fue definitivamente incorporada a la Corona en 1480; en 1525, Carlos V le concedió el título de ciudad ${ }^{9}$. Paralelamente, tuvo lugar el surgimiento de la nueva devoción, sin duda auspiciada desde el ayuntamiento, frente a la anterior de las Nieves (relacionada con los Manueles); de modo significativo, en 1526 se hacía cargo del lugar una comunidad agustina. Villena se incorporaba así al amplio movimiento de fundaciones conventuales del momento ${ }^{10}$, en una de

contiene documentos relativos a la primera etapa (1673-1770), si bien están pendientes de una explotación detenida.

7. Aunque los estudiosos locales (DOMEne Verdú, 14 (2011). SOler García, 2009) llegan a remontarse hasta 1474, en la información testifical evacuada el 23 de agosto de 1551 se tomó declaración a seis testigos, todos varones, de edades comprendidas entre $60 \mathrm{y}$ 90 años, que fueron interrogados sobre el particular. Todos abonaron la fundación en la última década del siglo XV; los mayores dijeron haber sido testigos directos de ella (Diferentes instrumentos... [1768]: 9-22). Aunque en la documentación del litigio de 1756-1757, se afirma que la erección de la primitiva ermita tuvo lugar en 1497 (Ibid.: 85), existe referencia documental de hallarse refugiada la población en la Fuente del Chopo, como consecuencia de un contagio, en 1490 (ORTUÑo MOLINA, 2003: 378). José María Soler dio por fundada la ermita en 1490 (SOLER GARCíA, 1974: 188-189).

8. Los libros de la única parroquia existente en ese momento -la de Santiago Apóstolfueron destruidos en la Guerra Civil, y la serie de actas municipales conservada se inicia -como hemos dicho- en 1564. Según la tradición, relatada en el siglo XVIII por el prior agustino en el manuscrito Prothocolo y libro de hacienda del santuario (GARCía, 1722), los villenenses se habían refugiado del contagio en la Fuente del Chopo (en las inmediaciones de la antigua laguna, a una legua de la ciudad), donde eligieron al azar a su nueva protectora, cuya imagen apareció de inmediato en el lugar donde aún hoy se levanta el santuario y se le sigue rindiendo culto (Diferentes instrumentos... [1768]: 8).

9. SOler GARCÍA, 1974: 506-508, 511-513. SOlER GARCÍA, 2009: 175, 229.

10. AtiEnZA, 2008: 33. Durante la Edad Moderna, Villena contó con otros dos conventos, ambos en el casco urbano o sus arrabales. El primero, el de las trinitarias, surgió en el contexto de la promoción de la villa a ciudad, en 1515 (SOLER GARCíA, 1974: 65); la fundación del segundo, el de los franciscanos descalzos, data de 1563, si bien se trasladaron a su nuevo convento en 1592 (Ibid.: 146-147. HENARES DíAZ, 2011: 208). En 1701 estuvieron a punto de establecerse los jesuitas, pero pese a contar con el 
Devociones, conflictividad y clima. Los santuarios de Nuestra Señora de las Virtudes (Villena) y San Cayetano (Crevillent) durante la Edad Moderna

tantas operaciones destinadas a respaldar y acrecentar la reputación, el honor y el prestigio de la localidad ${ }^{11}$. El esfuerzo resultó exitoso: a mediados del siglo XVI -siguiendo un patrón muy extendido- la devoción se había consolidado sobradamente, incluyendo las dos celebraciones anuales del 25 de marzo y del 8 de septiembre (con sus correspondientes romerías votivas al santuario encabezadas por la ciudad y el clero); la extensión del fervor a las poblaciones vecinas, la mayoría pertenecientes al Reino de Valencia ${ }^{12}$; y la fabricación de una extensa tradición milagrera, en una época en la que la geografía de los milagros tendía a coincidir con los intereses de los grupos dirigentes locales ${ }^{13}$.

\subsection{Los conflictos por el patronato entre la ciudad y el ordinario diocesano durante el Quinientos}

Desde temprana hora la ciudad de Villena desplegó amplios esfuerzos en la consolidación y defensa de su patronato sobre el santuario, frente a las que consideraba injerencias de otras instancias. Sin duda, los principales litigios sobre este particular se produjeron durante el siglo XVI. En 1507, D. Sancho García de Medina (maestrescuela de la catedral de Murcia, arcipreste y después arcediano de Villena), incorporó las rentas de Las Virtudes para la construcción de la nueva parroquia de Santiago ${ }^{14}$. En 1522, difunto ya el poderoso clérigo, y a súplicas del ayuntamiento, Carlos V solicitó de Adriano VI que la ermita no se anexase a ninguna otra iglesia, monasterio o persona ${ }^{15}$; el mismo día, el monarca encargó especialmente el asunto a su embajador

beneplácito del ayuntamiento y del clero secular, el proyecto quedó abruptamente interrumpido (vilar, 2000: 475-491).

11. ATIENZA, 2008: 21.

12. Diferentes instrumentos... [1768]: 8.

13. Una de las devociones de mayor relevancia en el área próxima (la de la Santa Faz de Alicante), de patrocinio municipal, proporciona un ejemplo perfecto de este hecho. Tras arduos esfuerzos, en 1490 Alicante obtenía el título de ciudad con los privilegios propios de tal condición. Oportunamente, un año antes habían tenido lugar los hechos milagrosos que dieron origen a la devoción de la Santa Faz (era difícil disfrutar de más alta mediación, como se encargaría de recordar el deán Bendicho a la ciudad de Valencia), y a su monasterio de la Santa Faz, encomendado primero a los jerónimos -que lo rechazaron-y finalmente -en 1518-a las clarisas gandienses (GIMÉNEZ LÓPEZ, 1989: 34).

14. DOMENE VERDÚ, 14 (2011): 219.

15. Valladolid, 22-X-1522. Diferentes instrumentos... [1768]: 5. AHMV, 1/11. 
en Roma, manifestándole que la ciudad era fundadora de la ermita, y que -siendo numerosas las limosnas- se hacía necesario cortar la «codicia» de algunas personas e instituciones eclesiásticas, que pugnaban para que el papa les anexase la ermita. En una formulación sistemáticamente repetida en los conflictos que vamos a referir, la misiva imperial apuntaba que el resultado de la entrega de los santuarios a manos inapropiadas era la malversación y el decaimiento de la devoción «como por experiencia se ha visto en estos Reynos, en otras [ocasiones] semejantes ${ }^{16}$. Según documentos posteriores, la gestión resultó positiva ${ }^{17}$.

Aún en tiempos del Emperador (1551), aunque en un periodo en el que -como se verá- no existía comunidad conventual y el santuario era gestionado directamente por la ciudad, esta solicitó autorización para afrontar los gastos en alimentos y músicas durante las romerías anuales, siempre con la justificación de ser necesario dicho gasto para que se mantuviese la devoción. La petición motivó una información testifical que cifró el coste anual por tales conceptos en torno a 5.000-6.000 maravedís, y evidenció el ejercicio del patronazgo municipal sobre la imagen y la ermita ${ }^{18}$. Más aún, la vinculación de la devoción a los eventos climáticos, especialmente el papel de la Virgen como intercesora en las necesidades de lluvia, ya aparece mencionada en estos documentos ${ }^{19}$.

Los conflictos más importantes por el control del santuario se produjeron entre la ciudad y los obispos murcianos a partir de la publicación del Tridentino en España, en 1564. El Concilio había promulgado un conjunto de decretos de reforma que podían ser, sin duda, ampliamente interpretados en favor de las atribuciones episcopales sobre el conjunto de los lugares piadosos

16. Diferentes instrumentos... [1768]: 5-6. AHMV, 1/12.

17. Diferentes instrumentos... [1768]: 13, 25-26. En la Real Provisión de 12 de noviembre de 1760 , se asumía que era público y notorio que por Real Cédula de Carlos V y Breve Apostólico, estaba mandada «la total, y absoluta inhivición», del ordinario diocesano de Cartagena «para el conocimiento de qualquier assumpto [...] concerniente a dicha Soberana Imagen [de las Virtudes], sus rentas, bienes, y limosnas, su inversión y destino [...] por estar considerado, como lo era dicho Patronato de Legos, e inmediatamente sujeto a la Jurisdicción Suprema del nuestro Consejo» (Ibid.]: 106-107). Estos documentos no se mencionan en ninguna otra de las fuentes manejadas.

18. Ibid.: 14. AHMV, 1/67. SOLER GARCÍA, 1974: 545-547 (Valladolid, 27-VII-1551).

19. Diferentes instrumentos... [1768]: 14. 
(incluidas las ermitas y santuarios, aunque no se mencionen explícitamente como tales). Así, se prohibía la obtención del patronato eclesiástico salvo en supuestos de fundación o dotación, reservándose en estos casos al obispo el nombramiento de patrono; además, el derecho de presentación de los candidatos al beneficio que correspondía a dicho patrono debía ser ejercido ante la dignidad episcopal, a quien correspondía la provisión del beneficio ${ }^{20}$. Por otro lado, se ordenaba que los obispos visitasen anualmente «todos los beneficios» ${ }^{21}$. Especialmente importante para nuestro asunto, fue la inclusión en dicha orden de los lugares de caridad que no estuviesen bajo la protección inmediata de los reyes, y además:

conozcan también de oficio, y hagan que tengan el destino correspondiente [...] las limosnas de los montes de piedad o caridad, y de todos los lugares piadosos, bajo cualquiera nombre que tengan, aunque pertenezca su cuidado a personas legas, y aunque los mismos lugares piadosos gocen el privilegio de esención [sic] sin que obsten costumbre alguna, aunque sea inmemorial, privilegio ni estatuto ${ }^{22}$.

Más aún, en el capítulo siguiente de la misma sesión se disponía que los administradores (eclesiásticos o seculares), de cualquier iglesia o lugar piadoso, diesen cuenta anualmente ante el ordinario, salvo que estuviese mandada otra cosa en las respectivas fundaciones ${ }^{23}$. Finalmente, en la sesión XXV se establecía el modo en que se había de probar el derecho de patronato, ordenando a los patronos que no se entrometieran en la cobranza de frutos, rentas y obvenciones, «sino dejen al cura o al beneficiado la distribución de ellos» ${ }^{24}$.

Con estos decretos como telón de fondo, ya en el pontificado de Arias Gallego (1565-1575) -que fue uno de los asistentes a la tercera sesión del Concilio-se produjo el primer enfrentamiento. En ejercicio de su patronato, la ciudad había venido nombrando diferentes cargos relacionados con el

20. Sesión XIV, 25-XI-1551, Decreto sobre la reforma, caps. XII y XIII (LÓPEZ DE AYALA, 1845: 175-176).

21. Sesión XXI (16-VII-1562), Decreto sobre la reforma, cap. VIII (LÓPEZ DE AYALA, 1845: 215-216).

22. Sesión XXII (17-IX-1562), Decreto sobre la reforma, cap. VIII (LÓPEZ DE AYALA, 1845: 239).

23. Ibid.

24. Sesión XXV (3 y 4-XII-1563), Decreto sobre la reforma, cap. IX (LÓPEZ DE AYALA, 1845: 372). 
santuario, señaladamente mayordomos (de entre sus regidores) y capellanes ${ }^{25}$. En esa situación -y siempre según la ciudad-al comenzar la década de 1570 el visitador del obispado de Cartagena, «socolor del Concilio Tridentino, se havía entremetido, y entremetía a poner, y criar un Capellán, que residiesse en la dicha Hermita [de las Virtudes], y cobrasse, y las llevasse dichas limosnas, y réditos de ella»; además, el obispo prohibió a la ciudad la administración del santuario, con apercibimiento de las correspondientes penas y censuras ${ }^{26}$. El asunto dio lugar, en 1571, a la petición de Villena al rey ${ }^{27}$ para que la amparase en su patronazgo y no se diese el pase a letra apostólica alguna favorable a la mitra. Las informaciones aportadas evidenciaron que nunca antes el obispo había nombrado ermitaño, santero o capellán de la casa, habiéndolo hecho por vez primera solo tres años antes, por la vía de dar un nuevo título al mismo que ya estaba nombrado por la ciudad para que pareciera puesto por el prelado, (según confesó el propio ermitaño) ${ }^{28}$.

Estando pendiente el pleito en el Consejo, Arias Gallego llegó a excomulgar a uno de los regidores de la ciudad y a un escribano. Ante la protesta municipal, aquel presentó otra petición indicando que la ermita estaba dentro del territorio del obispado, y que conforme a derecho y a los decretos conciliares, le correspondía la visita y administración. Asimismo, negaba absolutamente el patronazgo de la ciudad, puesto que la ermita y todos los bienes anejos habrían procedido de limosnas hechas por los vecinos de la ciudad y comarca. Consecuentemente, debían considerarse bienes espirituales, cuya administración le correspondía exclusivamente como prelado diocesano. Concluía reclamando su derecho a nombrar capellán que rigiese la ermita y administrase las limosnas, y solicitando la remisión de la causa al tribunal episcopal para su prosecución ${ }^{29}$. Sin embargo, el rey mandó que de inmediato se absolviese a los excomulgados y se alzasen las censuras ${ }^{30}, y$

25. AHMV, AACC, 25-VII-1564 y 22-III-1565. GARCÍA LUJÁN, 1988: 25-26. GARCÍA LUJÁN y GALBIS, 96/214 (2012): 88-89

26. Diferentes instrumentos... [1768]: 24. AHMV, 2/67. SOLER GARCÍA, 2009: 333-340.

27. Con evidente error, en Diferentes instrumentos... [1768]: 24 se da como año el de 1561.

D. Gonzalo Arias Gallego fue obispo de Cartagena entre 1565 y 1575.

28. SOlER GARCÍA, 2009: 333-340. GARCíA LUJÁN, 1988: 31-32.

29. Diferentes instrumentos... [1768]: 26.

30. Ibid.: 27. 
por el fallo del Consejo de 28 de septiembre de 1575 y la carta ejecutoria de 4 de diciembre de 1575, otorgada por Felipe II, se ordenaba que el obispo de Cartagena no impidiese a la ciudad de Villena la administración de la ermita ni el nombramiento de capellanes y mayordomos ${ }^{31}$. Esta victoria, que según decía años después un regidor, costó a la ciudad más de 500 ducados $^{32}$, fue tomada como fundamental por el concejo municipal, por entender que suponía el pleno reconocimiento de su derecho de patronato sobre el santuario ${ }^{33}$ Sin embargo, las disputas sobre la cuestión continuaron en la década siguiente, como pone de manifiesto un episodio estudiado detalladamente por el profesor R. Benítez ${ }^{34}$. Hacia 1586, el oriolano Juan Diego Mancebón (un clérigo con ínfulas de arbitrista), se había instalado en la ermita ${ }^{35}$. Aunque ignoramos bajo qué condiciones precisas se mantenía en el lugar, dos años más tarde Mancebón hizo llegar al rey un memorial ${ }^{36}$ en el que hablaba extensamente sobre las cosas del santuario, al tiempo que exponía su proyecto de reconvertirlo en seminario para la formación de los niños moriscos de las diócesis de Cartagena y Orihuela ${ }^{37}$.

Con independencia de su llamativo objetivo (nunca cumplido), la denuncia sirvió para que se solicitase información sobre el particular al entonces obispo de Cartagena, D. Jerónimo Manrique de Lara (1583-1591), quien a su vez ordenó la elaboración de una información testifical, instruida entre los días 3 y 10 de septiembre de 1588 por mosén Diego de Valera, arcipreste de Villena y comisario del Santo Oficio ${ }^{38}$. En su investigación, Valera tomó declaración a una docena de testigos -amén de manifestar su propia opinión ${ }^{39}-$,

31. Ibid.: 27-28. SOLER GARCÍA, 2009: 337. AHMV, 2/67.

32. Así lo afirmaba el regidor Juan Martínez de Olivencia (AHMV, AACC, 23-I-1592).

33. AHMV, AACC, 24-VIII-1593.

34. BENÍTEZ SÁNCHEZ-BLANCO, 1988: I, 287-300. Trabajo basado sobre documentos de la sección de Inquisición del AHN, libro 911, publicados íntegramente por dicho autor. El primero de ellos (ff. 681-682) es una carta del obispo de Cartagena, Manrique de Lara, en la que se ordena la realización de la testifical, e incluye el texto con las denuncias de Mancebón; el segundo (ff. 698), es un extracto del parecer del arcipreste Valera; el tercero (ff. 683-697) comprende todas las declaraciones de los testigos.

35. Ibid.: 288.

36. Ibid.: 1988: 297-299.

37. Ibid.: 295.

38. Ibid.: 289.

39. Ibid.: 299-300. 
representantes de lo que Benítez denomina gráficamente las «fuerzas vivas» de la ciudad en ese momento (entre los declarantes se encontraba al alférez mayor y alcaide del castillo, así como cuatro clérigos, todos varones, con una edad media de 54 años $)^{40}$.

De sus deposiciones, destacan -en lo que nos atañe- dos aspectos entrelazados. En primer lugar, las denuncias sobre estado moral en que se hallaba el santuario y el culto, que derivan en la elaboración de un verdadero catálogo -nada sorprendente, por lo demás- de excesos que debían cortarse ${ }^{41}$. La mezcla de elementos profanos y mundanos con lo sagrado es la habitual en estos casos: corridas de toros, bailes, comidas y bebidas, peleas, juegos deshonestos, presencia de «mugerzuelas» de día y de noche (incluso en el interior de la propia iglesia y claustro)... En definitiva, era el santuario «bodegón y cueba de abominaciones [...] y están las cosas tan depravadas que hay más necesidad de remedio que de recontarlas ${ }^{42}$. Por otra parte, aparecían las denuncias sobre el desgobierno existente el santuario. El propio arcipreste, tras hacer relación de los avatares del patronato, decía que el ayuntamiento administraba la casa «con mucha remisión y flaqueza y perversidad $»^{43}$. En cuanto a los testigos, abonaban la existencia de continuas desavenencias, disputas y competencias entre los miembros del concejo, queriendo el cargo de mayordomo «unos para sí, y otros para remediar a los parientes y amigos» ${ }^{44}$. En cualquier caso, los mayordomos eran «señores absolutos» de la ermita: no se tomaban -había dicho Mancebón- las cuentas sino unos a otros, se aprovechaban de los bienes y recursos del lugar, y se apropiaban de las limosnas para comerciar con ellas. La corrupción en la gestión -añadían los testigos- afectaba también a los recolectores de las limosnas, que entraban de pobres para salir ricos e incluso vivían amancebados en la propia ermita ${ }^{45}$. El ermitaño, como destaca R. Benítez, era la clave en esta cadena de intereses mutuos. La designación, efectuada por el ayuntamiento sin aprobación

40. Ibid.: 296.

41. Vid. PEÑA DíAZ, LXXIV: 777-806 (2014). Aunque referido al siglo XVIII, buena parte de los aspectos tratados en este trabajo son de aplicación en este momento.

42. BENÍTEZ SÁNCHEZ-BLANCO, 1988: 290.

43. Ibid.: 300.

44. Ibid.: 292.

45. Ibid.: 292-293. 
episcopal, constituía también motivo de alborotos y escándalos, puesto que para elegirlos solo se tenía en cuenta su afinidad a los dictados de los mayordomos y sus respectivos partidos ${ }^{46}$. El resultado era que la ermita, de poder tener unos ingresos anuales de hasta 1.000 ducados, carecía sin embargo de rentas fijas ${ }^{47}$, al tiempo que -sabedores de que «los administradores se comen las limosnas»-cundía el desánimo entre los devotos y decaían las ofrendas ${ }^{48}$.

La principal razón que -en las mentes, sin duda interesadas, de Mancebón y de los testigos de la información practicada- vinculaba corrupción moral, desgobierno, pérdidas económicas y, finalmente, decaimiento de la devoción y del santuario, era evidente:

La ocasión de tanto daño a salido de que en años pasados los del gobierno de aquella ciudad recibieron merced de Vra. M. del título de patrones de la hermita y con este escudo se an hecho las maldades que se hallarán [...], y tales que moverán las entrañas cathólicas de V. Md. para no permitir que tengan más ocasión los demonios con la hazienda y casa de Dios [de] granjear almas para el ynfierno [...] Al obispo, si les quiere estrechar, resisten con el amparo que V. Md. les tiene entregado al gobierno y administración de la hermita ${ }^{49}$.

Se hacía preciso, en definitiva, arrebatar «la dicha casa a estas gentes», para someterla al estricto control del ordinario diocesano. De hecho, no podemos descartar que se tratara de una operación concertada, o de la que -al menosel obispo fuera conocedor: según Mancebón, Manrique de Lara-que en ese momento se hallaba en Madrid- tenía «ya noticia de muchos desconciertos que allí se hazen y ayudará lo posible para que se salga con esta empresa ${ }^{50}$.

Como veremos poco más adelante, una parte de los regidores villenenses compartirían parte del diagnóstico efectuado por Mancebón; no así, obviamente, sus soluciones: la ciudad lo despidió sin contemplaciones, cortando en seco la cuestión ${ }^{51}$. Añadamos que, si bien no podemos establecer una relación clara con el memorial del oriolano (cuya fecha exacta, más allá del año, se

46. Ibid.: 293-294.

47. Ibid.: 294.

48. Ibid.: 294-295.

49. Ibid.: 298.

50. Ibid.: 298.

51. El mismo día que se cerraba la información testifical, el ayuntamiento acordaba exhortar a Mancebón para que recogiese la ropa y demás enseres que tuviese en el santuario, pretextando que ya se había nombrado clérigo para la casa. Se le daban dos días de 
desconoce), simultáneamente se estaba procediendo a un estrecho control de los gastos relacionados con el santuario: como ya sucedió en 1551, en 1588 Villena tuvo que solicitar de nuevo autorización real para hacer frente al pago, con cargo a los propios y rentas de la ciudad, de los gastos derivados de las festividades de la Virgen, en particular para «dar de comer a los rreligiosos y gente pobre que acudieren a ella» ${ }^{52}$.

\subsection{El santuario como centro conventual}

\subsubsection{Dificultades y enfrentamientos en los establecimientos iniciales}

Pese a lo indicado, para la ciudad una situación de administración directa distaba de resultar óptima. En primer lugar, constituía una fuente de problemas. En el ejercicio de su patronato, el concejo nombraba diferentes cargos: mayordomos y diputados (entre los integrantes del propio cabildo, para el control económico y lo relativo al patronato y las festividades), así como capellanes y predicadores (para atender el culto) ${ }^{53}$. Por supuesto, las denuncias de Mancebón respecto de los manejos interesados de mayordomos y ermitaños contenían su parte de verdad, dadas las habituales e inevitables banderías locales. Además, no es difícil colegir de la documentación que también el nombramiento de capellanes podía volverse problemático en múltiples circunstancias. En marzo de 1569 se produjo una discusión entre los regidores sobre este asunto: se consideraba que la persona que atendía el cargo desde hacía siete u ocho años (el reverendo Francisco Navarro) no era «letrada»

plazo para salir y se añadía que si pudiera tener algún nombramiento de la ciudad, había quedado revocado y sin valor. AHMV, AACC, 10-IX-1588.

52. SOLER GARCÍA, 1974: 567-569. SOLER GARCíA, 2009: 272-273. La cuestión se había originado al haber quedado de manifiesto, en la revisión de las cuentas municipales efectuada por jueces reales, que Villena carecía de autorización para el gasto de 100 ducados anuales (1.100 reales) que «desde tiempo inmemorial» venía haciendo por tales conceptos. La petición se aprobó, reduciendo el gasto total a 700 reales, el 24 de agosto de 1588 (es decir, en los días que mediaron entre la carta del obispo ordenando la realización de la información testifical, y la práctica efectiva de la misma).

53. Los nombramientos de los dos primeros cargos constan ya en los primeros libros de actas capitulares conservados (AHMV, AACC, 25-VII-1564 y 22-III-1565). En los documentos de 1593, se menciona al mayordomo de la Casa de las Virtudes y al regidor encargado por el concejo para la defensa de las cosas tocantes al patronato. Diferentes instrumentos... [1768]: 50 
y que se precisaba un teólogo y «sermoneador» hábil. A favor de Navarro se manifestaron el regidor que ejercía de mayordomo de Las Virtudes y un jurado; partidarios del P. Segura (natural y vecino de la ciudad), o de otra persona -en todo caso, un predicador docto- eran otros cinco regidores y el alguacil. La clave de la cuestión la expresó el regidor Hernando de Medina -que también había sido mayordomo de la casa-, pues colocar a una persona con el perfil de Segura -dada su reconocida autoridad-incidiría en el aumento de la devoción (y añadimos, de las necesarias limosnas) ${ }^{54}$. Más aún, como ocurrió en el mencionado año de 1588, bien por las erráticas designaciones consistoriales, bien por hallarse acomodados en otros empleos -o quizá por la conflictiva situación-, no todos los clérigos aceptaban el nombramiento ${ }^{55}$; o efectuado este, lo dejaban pronto por otro desempeño que consideraban más favorable; o, simplemente se revelaban como no idóneos para el cargo ${ }^{56}$.

Frente a todo ello se alzaba la opción de ceder el santuario a una comunidad conventual. Evidentemente, tal salida entrañaba notables ventajas prácticas: permitía mantener el patronazgo, desentenderse de la atención cotidiana, y sostener la devoción. Pero por encima de todo se encontraban otros factores de mayor peso: toda ciudad que se preciara pretendía competir en la nobleza de sus moradores, el número de santos nacidos entre sus hijos, y -en fin- la posesión de una buena dotación de conventos ${ }^{57}$. Los centros conventuales, así pues, añadían blasones de nobleza e ilustraban a la ciudad y a sus gobernantes. De modo que el santuario de Las Virtudes estuvo sujeto a un régimen conventual durante la mayor parte de la Edad Moderna. Sin embargo, esta alternativa-como vamos a ver-tampoco estuvo libre de generar situaciones conflictivas.

54. AHMV, AACC, 27-III-1569.

55. En febrero de dicho año, renunció el capellán del santuario por haber sido nombrado para la parroquial de Santa María de Villena. Pese a los diversos intentos y designaciones, no se cubrió la plaza hasta junio, en que -de forma excepcional-fue el corregidor quien nombró sustituto, con aprobación de la ciudad, por un año y con una asignación de 250 reales (AHMV, AACC, 15-II, 3-III y 27-VI-1588).

56. GARCía LujÁN, 1988: 25-26. GARCía LujÁN y GALBIS, 96/214 (2012): 88-89.

57. Cutillas, 569. A propósito de la concesión a la ciudad de Alicante del título de Muy Noble y Muy Ilustre, y a sus justicias y jurados del tratamiento de señorías, el conde de Cardona -como delegado de los jurados valencianos- se oponía arguyendo precisamente la escasez de tales elementos en el caso alicantino. 
Ya en la carta enviada en 1522 por Carlos V al embajador en Roma constaba que era intención de la aún villa «poner Religiosos, e Clérigos para el servicio de ella, e para coger las limosnas que se hacen ${ }^{58}$. Cuatro años más tarde, recién obtenida la nueva categoría ciudadana, tal intención se concretaba con el establecimiento en la casa de una comunidad de agustinos murcianos (pertenecientes a su provincia de Andalucía), reservándose el ayuntamiento el derecho de patronato sobre la imagen mariana y todos los bienes del lugar ${ }^{59}$. La comunidad permaneció en la casa apenas unos años, pues la abandonaron en 1542, por propia decisión de la orden, que en tiempos de auge de las observancias, alegaba no querer mantener casas pequeñas, donde la disciplina, con apenas unos pocos religiosos de escasos de recursos, se resentía gravemente ${ }^{60}$. Tanto, que se produjeron «ciertas revoluciones» en las que se llegó a matar a uno de los frailes, amén de plantearse fuertes discrepancias sobre la liquidación de los efectos cedidos ${ }^{61}$. En cualquier caso, los agustinos se reintegraron a su convento de Murcia, dejando los bienes que no fueran de su propiedad -junto con la casa- «a la disposición del ordinario o a quien le competiere», y prometiendo que «agora, ni en ningún tiempo no irán, ni vendrán contra esta escritura [de renuncia]», y en particular, contra la ciudad ${ }^{62}$.

Como ya hemos visto, con la partida de los agustinos la ciudad continuó nombrando a capellanes y mayordomos. Sin embargo, parece que en el curso del conflicto ocurrido en 1588 ya se consideró la posibilidad de atraer a una comunidad conventual, pues en septiembre el ayuntamiento decidió negociar con el provincial de los franciscanos descalzos las condiciones para que se estableciera en Las Virtudes una comunidad de las afamadas clarisas de

58. Diferentes instrumentos... [1768]: 5. AHMV, 1/12.

59. Diferentes instrumentos... [1768]: 91. La escritura se otorgó el 3 de diciembre de 1526. El referido manuscrito del prior agustino (GARCÍA, 1722) proporciona un relato del establecimiento acorde con el maravillosismo propio del género. El motivo habría sido prestar una mejor asistencia a la Virgen, que hasta entonces estaba atendida por un solo ermitaño (es decir, rendirle un culto acorde con su rango); la comunidad agustina habría sido elegida, por la propia Virgen, a suertes entre las Órdenes mendicantes (GARCÍA LUJÁN, 1988: 27-28).

60. AHMV 1/51. Diferentes instrumentos... [1768]: 46-47. DOMENE VERDÚ, 14 (2011): 222. 61. AHMV, AACC, 23-XII-1591, intervención del regidor Cebrián Oliver.

62. Diferentes instrumentos... [1768]: 46-47. SOLER GARCÍA, 2009: 340-345. AHMV, 1/51. 
Gandía, y -llegado el caso- enviar comisionados para tratar el negocio con el titular de dicho ducado ${ }^{63}$.

La iniciativa no se llevó a término, pero evidencia que el ayuntamiento villenense estaba abierto a la opción conventual, máxime teniendo en cuenta la disponibilidad de un edificio al efecto. En 1591, con licencia y comisión del ordinario diocesano, se encargó al arcipreste de Villena -el mencionado Diego de Valera- que diese posesión legal del santuario, de nuevo, a los agustinos calzados; pero en lugar de volver a tratar con los murcianos, se entablaron negociaciones con los conventos de Alcoi y Xàtiva ${ }^{64}$. Y así, en las vísperas de la Navidad de 1591, se presentó en el cabildo municipal el provincial de los valencianos (propiamente, de su provincia de Aragón) y pidió formalmente la casa de Las Virtudes para convento de su orden «con algunas razones que propuso». No había, sin embargo, unanimidad en el seno del ayuntamiento, y menos aún si se trataba de los agustinos. En la discusión subsiguiente actuó como ponente el capitán Pedro Rodríguez Navarro, manifestando su posición favorable pues solucionaría «algunos inconvenientes [...] en la administración» del santuario y mejoraría el uso que se daba a las limosnas. Eso sí, teniendo sin duda presentes los recientes pleitos, la cesión solo debía hacerse con el beneplácito episcopal y una vez establecidas las debidas capitulaciones con la nueva comunidad, que dejasen claro el patronazgo municipal del santuario. La mayor parte de los miembros de la corporación estuvieron de acuerdo, expresando un sentimiento común respecto de no hallarse la casa en el adecuado orden espiritual y moral; alguno también manifestó sus escrúpulos por estar las limosnas en manos de legos. Sin embargo, otros cuatro regidores (Pedro Miño, Juan de Santolín, Cebrián Oliver y Martín Alonso de Medina) no estaban en absoluto de acuerdo. Recordaban las circunstancias en las que la anterior comunidad agustina tuvo que abandonar la casa, violencias incluidas, declinaban toda responsabilidad si se les cedía de nuevo, se hacían

63. AHMV, AACC, 25/09/1588. SOlER GARCíA, 2009: 340. Sobre las clarisas de Gandía, muy estrechamente relacionadas con la familia Borja, vid. AMORÓS, 1981. Dentro de su dinámica expansiva, en 1518 se habían hecho cargo del monasterio alicantino de la Santa Faz (CuTILlas, 1995: 43, 106).

64. Diferentes instrumentos... [1768]: 32-37. El dinamismo de la orden la llevó a duplicar en la Edad Moderna la presencia que había tenido en los tiempos medievales (ATIENZA, 2008: 52). 
eco incluso de cierta oposición popular, y el último de ellos proponía que no hubiera frailes, sino cuatro clérigos naturales de Villena que administrasen el lugar ${ }^{65}$. Un mes después, un regidor que no estuvo presente en la anterior sesión (Juan Martínez de Olivencia) manifestó en una nueva sesión capitular su rotunda disconformidad con la decisión: en la ocasión anterior, la ciudad había resultado «infamada»-pues, según decía, los agustinos habían robado en unos bienes levantados por el pueblo- y de modo desafiante exigía que no se les volviese a ceder la casa sin antes informarse de cómo les iba en los conventos de Agres, Biar, Alcoy, Almansa, La Roda y San Clemente; y menos aún, sin dar aviso a Yecla, Caudete y demás lugares a la redonda, ya que también contribuían a sustentar el santuario con sus limosnas. Para remachar el clavo, el indignado Martínez de Olivencia recordaba lo oneroso que resultó recobrar el santuario de manos del obispo, y que si la casa no se hallaba correctamente ordenada, se quitasen amas y mozos «hasta que acierten en buena gente» ${ }^{66}$. La ofensiva no cesó. Pocos días más tarde, el alcalde ordinario Pedro Martínez de Olivencia prohibía que ningún regidor osara dar posesión del santuario sin licencia del rey, como patrono del mismo, bajo pena de 50.000 maravedís para la Cámara. La justificación, que sonaba más bien a amenaza, era la de «quitar ocasiones para que no se revuelva la ciudad ${ }^{67}$. Jurídicamente, mientras los partidarios de no ceder el santuario argumentaban que la ciudad era patrona en nombre del rey «como patrón que es de las Iglesias de España ${ }^{68}$, sus oponentes apelaban el mandato del alcalde indicando que según la legislación, lo acordado en un cabildo no se podía deshacer «si no fuere con más copia de ayuntamiento ${ }^{69}$. Pese al evidente contraste de pareceres, se impuso el sector mayoritario, sin que la cuestión volviera a discutirse entre los capitulares. Tampoco planteó problemas, al menos inicialmente, el ordinario diocesano en el proceso de establecimiento de los conventuales.

65. AHMV, AACC, 23-XII-1591.

66. AHMV, AACC, 23-I-1592.

67. AHMV, AACC, 30-I-1592.

68. AHMV, AACC, 30-I-1592, intervención del regidor Martín Alonso de Medina. Nueva Recopilación.

69. AHMV, AACC, 30-I-1592. Curiosamente, fue Pedro Miño, que se había mostrado muy escéptico cuando se planteó la cesión a los agustinos, quien puso sobre la mesa este argumento. 
Las necesarias capitulaciones se firmaron en Alcoy el 4 de febrero de $1592^{70}$. En ellas, se fijaba ante todo el patronazgo, dominio y propiedad de la ciudad sobre la casa, bienes (raíces, censos, muebles y semovientes) y los ornamentos que se entregaban a la comunidad conventual. De tales bienes, tanto presentes como futuros, se cedía a los agustinos el uso y la posesión, pero esta sería revocable en ciertos supuestos: que el número de individuos de la comunidad fuese inferior a ocho ${ }^{71}$, o que los frailes «desamparasen la casa». Anualmente, se haría inventario económico y se llevaría un libro para la puntual anotación de todos los ingresos y limosnas. Cada tres años, el convento rendiría cuentas ante los mayordomos nombrados por la ciudad al efecto ${ }^{72}$, y de la gestión de todo ello los conventuales darían las oportunas finanzas. Las cuestiones protocolarias y ceremoniales, como correspondía al honor de convento y de la ciudad, también quedaron detenidamente descritas. El ayuntamiento reservó para sí algunos espacios en el santuario, especialmente en los días de romería, y tanto en dichas festividades como cuando se ofreciere «por necesidad de agua, o de salud, o otra causa» ${ }^{73}$-en que la ciudad con el clero y cabildo se desplazaba en procesión a la casa- sería recibida por los frailes con el protocolo que quedaba descrito. Cuestión fundamental, en ningún caso podría trasladarse definitivamente la imagen o el santuario a la ciudad o a ninguna otra parte, «aunque para ello tenga licencia de esta ciudad». Por último, los agustinos renunciaban a su propio fuero sometiéndose a la jurisdicción ordinaria diocesana; y se comprometían a aportar en el plazo de seis meses la necesaria confirmación de las capitulaciones por parte del provincial o general de su orden. Vista la escritura de fianzas (aportadas mediante hipotecas sobre censales por un principal de 2.224 libras valencianas ${ }^{74}$ ), con la mencionada comisión episcopal y auto del alcalde ordinario Diego de Bolimbro, se les dio efectivamente posesión, el inmediato día 5 de febrero ${ }^{75}$, en un acto repetido

70. Diferentes instrumentos... [1768]: 32-36, 37-41.

71. De los ocho, cuatro debían ser presbíteros, más un predicador (también sacerdote).

72. El nombramiento de estos cargos continuó durante el siglo XVIII. En su última formulación, tras el pleito de 1756-1757, estos eran dos regidores encargados de tomar las cuentas, dos comisarios de festividades (incluyendo las rogativas) y el regidor al que correspondía custodiar la llave del sagrario del santuario los Jueves Santos.

73. Diferentes instrumentos... [1768]: 34.

74. Ibid.: 42. El beneficiario de todos los censales era el convento agustino de Alcoy. 75. Ibid.: 37, 44-45. SOlER GARCÍA, 2009: 345-352. AHMV, 3/30. 
sendas veces de forma idéntica: la primera acompañados los frailes por el arcipreste Diego de Valera, y la segunda por el alguacil mayor de la ciudad, Sancho de Valera, como representantes de ambas autoridades ${ }^{76}$.

Esta nueva situación se vio alterada bruscamente el año siguiente, pues el 25 de agosto de 1593 los agustinos aragoneses se vieron expulsados del santuario "violentamente, y con mano armada ${ }^{77}$ por sus hermanos murcianos, con mandato del obispo de Cartagena, D. Sancho Dávila ${ }^{78}$. El concejo villenense -que en cabildo del día anterior quedó enterado de la orden episcopal ${ }^{79}$ - entendió que de este modo se le estaba despojando del patronato y posesión del santuario, al no disponer los frailes murcianos del nombramiento de la ciudad. En consecuencia, solicitó al alcalde mayor el amparo de sus derechos ${ }^{80}$, en virtud del cual se requirió a los frailes y al obispo para que se restituyese la situación anterior, comunicándole la ejecutoria real sobre el patronato del lugar y las capitulaciones del año anterior ${ }^{81}$. Así pues, toda la operación de desalojo había contado con la protección y el mandato episcopal. Respondió el mitrado diciendo desconocer la ejecutoria, pero alegó que en todo caso esta se obtuvo en periodo de sede vacante ${ }^{82}$, por lo que no se efectuó entonces diligencia alguna de defensa por parte de la dignidad episcopal; que no había lugar a que renunciase a sus derechos, pues la ermita estaba en territorio del obispado y por tanto su administración y visita le correspondían, conforme al Concilio; y que estando de acuerdo en que debía haber allí religiosos agustinos, era «más conveniente, y más a propósito que fuessen castellanos, por ser de un mismo lenguaje, y estar la dicha Hermita en estos Reynos de Castilla» ${ }^{83}$.

76. AHMV, 3/31, 33. Se trata de unas capitulaciones al uso, e incluso un tanto imprecisas. Vid. ATIENZA, 2008: 298-306, 398-399, 410-414.

77. Diferentes instrumentos... [1768]: 29, 50. AHMV, 3/42.

78. Diferentes instrumentos... [1768]: 52. AHMV, 3/38. D. Sancho, fundador también del Seminario Conciliar de San Fulgencio de Murcia, constituye «el paradigma de prelado de la Reforma católica» en la diócesis murciana (IRIGOYEN y GARCíA, 22 (2002): 17.)

79. AHMV, AACC, 24-VIII-1593.

80. Diferentes instrumentos... [1768]: 52. AHMV, 3/39, 3/40, 3/41.

81. Diferentes instrumentos... [1768]: 52.

82. Era cierto: Arias Gallego falleció el 28 de abril de 1575 y su sucesor, Gómez Zapata, no fue preconizado hasta el 11 de abril de 1576.

83. Diferentes instrumentos... [1768]: 30. 
Devociones, conflictividad y clima. Los santuarios de Nuestra Señora de las Virtudes (Villena) y San Cayetano (Crevillent) durante la Edad Moderna

El asunto dio lugar a una información testifical (con cinco comparecientes), instada por el ayuntamiento al alcalde mayor, que confirmó los hechos del desalojo (los murcianos se presentaron acompañados de dos guardias provistos de escopetas), así como la tensión del momento, que condujo a insultos verbales e incluso a que se produjesen algunos escopetazos ${ }^{84}$. Aunque la ciudad hizo una última petición al rey para restituir a los valencianos en la posesión del convento ${ }^{85}$ y se iniciaron diligencias litigiosas ${ }^{86}$, el asunto pronto se silenció, imponiéndose la paz por la vía de los hechos: los agustinos murcianos continuaron en Las Virtudes, pero la ciudad no les concedió su autorización expresa ${ }^{87}$. El asunto volvería a plantearse en un nuevo litigio durante los años de 1750, pero el siglo XVI, pese a todo, no se había cerrado del todo negativamente para los intereses episcopales.

\subsubsection{El Setecientos: los conflictos entre la ciudad y la comunidad agustina}

Durante el siglo XVII, conocemos algún incidente de escasa trascendencia relacionado con el santuario. Como refirió Molina Puche al estudiar la conflictividad registrada entre los delegados regios y la oligarquía local, en 1618 un grupo de regidores encabezado por D. Juan Martínez de Erquiaga (alcalde ordinario por el estado noble), se enfrentó -espada en mano-al alcalde mayor

84. Ibid.: 56-59. SOLER GARCÍA, 2009: 356-357, 361.

85. Diferentes instrumentos... [1768]: 60-61. AHMV, 3/43. Pese a constar en la guía del AHMV con dicha signatura, el documento original está extraviado.

86. De hecho, se había nombrado procurador ante el Consejo Real (AHMV, AACC, 7-IX-1793).

87. Diferentes instrumentos... [1768]: 53. SOLER GARCÍA, 2009: 357. El AHMV conserva algunos expedientes sobre este particular (DOMENE VERDÚ, 14 (2011): 227). En el pleito de 1756-1757, la ciudad insistiría en que habían sido tolerados como «meros detentores» (Diferentes instrumentos... [1768]: 72) sin gozar de ningún tipo de permiso, «desentendiéndose de la sugeción, y reconocimiento que deben tener, para [...] la dación de las cuentas de las limosnas [y] apropiándose un derecho de que prescinden, lo distribuyen, y enagenan tan libre, y desenfrenadamente, que sobre el fraude, que ocasionan al caudal, y tesoro de dicha Imagen, es una usurpación conocida de que compete a la Ciudad» (Ibid.: 86). Estos extremos serían reconocidos por los propios conventuales en las capitulaciones firmadas con la ciudad en 1756, «por cuyo defecto como tan indispensablemente necessario, se hallan inhábiles para perseverar en él [convento], sin que les pueda coadyubar para su manutención, el transcurso, aunque fuere de muchos años, y aun siglos por defecto de dicho título» (Ibid.: 62). 
del partido, Martín López de la Morena. El hecho tuvo lugar en el santuario, en plena feria de septiembre, donde ambos alcaldes disputaron sobre el derecho a presidir las fiestas. Martín López resultó con una cuchillada en la cabeza, y Martínez lesionado en un brazo. El corregidor actuó expeditivamente, deteniendo a este último y a varios regidores; remitida la causa al Consejo, el alcalde ordinario fue inhabilitado para ejercer oficios públicos durante cinco años ${ }^{88}$.

También se registró algún choque entre la ciudad y el clero local, donde la primera entendía que de un modo u otro se estaban lesionando sus derechos de patronazgo ${ }^{89}$. Sin embargo, la devoción se mantuvo plenamente activa, y en cuanto al santuario, se ha conservado documentación relativamente abundante sobre la comunidad agustina, especialmente sobre su comportamiento económico y financiero ${ }^{90}$. Por lo demás, el patronato de la ciudad se vio reforzado con un nuevo elemento simbólico que se mantendría al menos durante el resto de la Modernidad: en marzo de 1640 se instauró la costumbre de entregar la llave del sagrario del santuario, una vez cerrado al concluir los oficios del Jueves Santo, al caballero regidor que -por turno obligatoriorepresentaba a la ciudad en dicha función ${ }^{91}$. La cuestión generó un incidente en 1676, cuando el prior se negó a hacer entrega de la llave alegando una disposición de la junta de cardenales, comunicada por el ordinario eclesiástico, en la que se prohibía entregarla a ningún seglar. En respuesta, la ciudad acordó estrechar el control sobre la comunidad -en manifestación de su patronato-y escribir al provincial, comunicando lo sucedido así como quejándose por el

88. Molina PuChe, 2005a: 68.

89. GARCÍA LuJÁN, 1988: 37-38, 49-50.

90. Los correspondientes al siglo XVII en las siguientes signaturas del AHMV: 3/59, 4/1, 4/8, 4/10, 4/56, 4/85, 5/2, 5/39, 5/47, 6/4, 6/15, 7/10, 7/11, 7/12, 7/37, 7/47, 8/4, 8/9, $8 / 22$, y $8 / 23$. Buena parte son escrituras de censos a favor de la comunidad. Este tipo de información se prolonga en los fondos del mismo archivo correspondientes al siglo XVIII, poniendo de manifiesto un importante patrimonio en fincas rústicas y urbanas, ganados e inversiones financieras. A destacar el inventario efectuado por el prior en 1722 (GARCÍA, 1722).

91. GARCía LujÁn y GALBIS, 96/214 (2012): 24. AHMV, AACC, 10-III-1640. La llave se devolvía al prior del convento al abrir de nuevo el sagrario el Viernes Santo. 
deficiente servicio que prestaban los conventuales ${ }^{92}$. El provincial terminó ordenando a los frailes que respetasen la costumbre, puesto que el decreto referido no estaba recibido en España ${ }^{93}$.

Más conocidos resultan los choques ocurridos durante el Setecientos entre los conventuales y la ciudad. Aún sin llegar al conflicto, en 1727 aquellos solicitaron el traslado de la imagen de la patrona a la iglesia del Hospital de la Concepción (en el casco urbano) y el de su comunidad a la ermita de San Sebastián. Las razones esgrimidas eran dos: el estado de «ruina» del edificio, y la insalubridad del emplazamiento, causada por la inmediata laguna ${ }^{94}$. Los frailes -que en principio planteaban la medida como temporal, hasta que la ciudad decidiese qué medidas adoptar ante ambos problemas- contaban con el apoyo de su provincial, que lo expresó mediante carta al ayuntamiento. La corporación, sin embargo, se opuso en redondo: la ubicación del santuario había sido elegida por la propia Virgen, por lo que un traslado así resultaría en extremo disonante para los devotos y «daría lugar a que menguase la devoción hacia Ella» ${ }^{95}$. La sombra de potenciales conflictos ya se manifestó en la réplica municipal, donde se negaba que el edificio se encontrase en tan malas condiciones; más aún, se decía que cuanto recogían los conventuales en limosnas no lo invertían en los necesarios arreglos ${ }^{96}$. Así las cosas, el año siguiente el prior agustino comunicó a la ciudad que su comunidad no acudiría a la ciudad en las fiestas de septiembre, por la extrema pobreza en que decía se hallaban ${ }^{97}$. Y una vez pasada la fiesta, el prior volvía a escribir al concejo para solicitar de este que le diese traslado exacto de las obligaciones que les correspondían como conventuales. Faltos de documentación al efecto, en la deliberación subsiguiente los capitulares acordaron consultarlo con sus compañeros más ancianos y conocedores de toda la relación entre convento y ciudad $^{98}$. En 1729, el ayuntamiento aún no había dado respuesta al prior, y

92. AHMV, AACC, 1-IV-1676. Por vez primera, convienen en reconocer los «papeles antiguos» que confirmaban su patronato.

93. García LuJÁN y GALBIS, 96/214 (2012): 24-25. AHMV, AACC, 1 y 5-IV y 11-VI-1676.

En este último cabildo se exigía una acción ejemplarizante sobre el prior del convento.

94. AHMV, AACC, 23-XI-1727, SOLER GARCÍA, 2009: 357-360.

95. AHMV, AACC, 08-12-1727, GARCÍA LUJÁN, 1988: 61-62.

96. AHMV, AACC, 8-XII-1727.

97. AHMV, AACC, 4 y 5-XI-1728.

98. AHMV, AACC, 11-IX-1728. 
en 1730 se produjo un incidente con los frailes con motivo de haber llevado estos la Virgen a Villena sin el protocolo debido ${ }^{99}$. Así pues, confiado todo exclusivamente a la costumbre más que centenaria, quedaba sembrado el terreno para futuros enfrentamientos.

Pese a todo, aún pasó más de un cuarto de siglo hasta que se produjo el más sonado (y último digno de mención) del siglo XVIII. El 27 de enero de 1756, los agustinos -sin comunicarlo previamente al ayuntamiento, y como ya habían hecho en 1730- decidieron unilateralmente trasladar la imagen, implorando el agua del cielo, al núcleo urbano. La justificación era la de evitar gastos innecesarios «y sí solo excitar una verdadera contrición mediante algunas pláticas, y principalmente con la visita de María Santísima, con lo que finalizada la procesión y recibida de Nuestra Patrona la bendición, nos volveremos a esta casa». Ante lo unilateral y precipitado de la decisión, que rompía el protocolo que regía las rogativas y los traslados de la imagen al poblado, esta vez la ciudad reaccionó de inmediato, enviando «recado político» al prior para que suspendiera la función hasta que se pudiera efectuar de común acuerdo y con el debido y acostumbrado culto. Como quiera que el prior insistió en no variar su propósito, el ayuntamiento envió a un diputado con amplios poderes para que viera el modo de suspender el traslado, y nombró dos comisarios para que «por todos los medios prudentes posibles» impidieran la operación ${ }^{100}$.

Aunque la imagen mariana ya se encontraba dispuesta para ser sacada del santuario, el prior terminó por ceder: se mostró «muy obsequioso», envió una carta disculpándose y se comprometió ante los comisarios nombrados al efecto a no moverla nunca más sin autorización, reconociendo que las decisiones sobre el traslado de la Virgen incumbían privativamente a la ciudad ${ }^{101}$. Sin embargo, solo tuvieron que pasar unos pocos días para que el conflicto se reactivase. En el cabildo del inmediato 28 de enero, el ayuntamiento acordó traer la imagen en rogativa el $1 .^{\circ}$ de febrero, y procedió -como de costumbrea nombrar los comisarios que habían de encargarse de los actos ${ }^{102}$. Ocurrió

99. AHMV, AACC, 5-XI-1730.

100. AHMV, AACC, 27-I-1756. SOLER GARCÍA, 2009: 360.

101. AHMV, AACC, 28-I-1756.

102. Diferentes instrumentos... [1768]: 70. AHMV, AACC, 28-I-1756. SOLER GARCÍA, 2009: 361. 
que el día señalado amaneció lloviendo, por lo que se decidió suspender la función; sin embargo, para mayúscula sorpresa de los munícipes, el prior respondió que de todos modos procedería a trasladar la Virgen, y «que si la Ciudad quería salir a recibirla lo hiciesse» ${ }^{103}$. Introdujeron la imagen - «con la mayor ignominia, falta de veneración, y escándalo de aquel Pueblo, y sus circunvencinos» ${ }^{104}-$ en la galera del convento y, atravesando un arroyo peligrosamente crecido, se plantaron en Villena. En evitación de un posible tumulto popular, ambos cabildos -civil y eclesiástico- se vieron forzados a salir precipitadamente a recibir a la patrona, que fue depositada en la ermita de San Sebastián, para trasladarla al día siguiente al templo de Santiago. La ciudad le dedicó, en desagravio, un novenario de sermones, cumpliendo así con la práctica habitual cada vez que tenía lugar un traslado de la Virgen a Villena ${ }^{105}$.

Sin embargo, las espadas seguían en alto. El ayuntamiento, que acumulaba quejas contra los religiosos por la administración que hacían de las limosnas y del santuario, entendía que se había atentado directamente contra su patronato, y no estaba dispuesto a dejar pasar la ocasión para clarificar definitivamente la relación con el convento ${ }^{106}$. En consecuencia, decidió plantear un nuevo otorgamiento de capitulaciones, y no devolver la imagen al santuario mientras dicho acuerdo no se hubiese firmado y asegurado. Por su parte, los religiosos actuaron con evidente doblez. Sobre el terreno, «advirtiendo su excesso dicho Prior y Comunidad» ${ }^{107}$, se ofrecieron a entenderse de nuevo con la ciudad ${ }^{108}$. Como resultado, el 24 de marzo de 1756 firmaron una escritura de convenio mediante la cual se comprometían a guardar -con muy escasas diferencias- los capítulos y condiciones con que entraron, en el ya lejanísimo

103. Diferentes instrumentos... [1768]: 70.

104. Ibid.: 70-71.

105. Ibid.: 71. SOLER GARCÍA, 2009: 361.

106. Fue en este momento cuando se adoptó la decisión de reunir todos los papeles existentes sobre el particular en el archivo municipal, para darlos a conocer a los frailes e imprimirlos, que dio lugar a la publicación de los Diferentes instrumentos... [1768] que venimos siguiendo (AHMV, AACC, 28-I y 21-III-1756).

107. Ibid.: 88 .

108. El provincial, en contestación a una carta remitida por el ayuntamiento, se ofreció a mediar para solucionar amistosamente el incidente (AHMV, AACC, 15-III-1756). 
Devociones, conflictividad y clima. Los santuarios de Nuestra Señora de las Virtudes (Villena) y San Cayetano (Crevillent) durante la Edad Moderna

1592, sus hermanos valencianos ${ }^{109}$. De acuerdo con lo pactado, si en el plazo de sesenta días la escritura no había sido ratificada por el provincial, la comunidad perdería sus derechos y la ciudad podría entregar el santuario a las personas o comunidades regulares o eclesiásticas que fuesen de su agrado. Por la vía de los hechos, como medida de presión y de afirmación indiscutible de su patronato, la ciudad retendría la imagen (en la arciprestal de Santiago) mientras no llegase la necesaria aprobación de la orden, privando con ello a los conventuales de la posibilidad de percibir limosnas, que pasarían a ser administradas interinamente por los comisarios designados por la ciudad ${ }^{110}$.

Pese a su aparente sumisión, los religiosos habían decidido no permanecer pasivos ante las actuaciones municipales. Por una parte, decidieron ganar tiempo, demorando la aprobación del provincial; por otra parte, se aprestaron a litigar. Para ello, inicialmente intentaron conseguir la nulidad de la escritura de capitulaciones, manifestando haberla firmado bajo presión ${ }^{111}$. En cualquier caso, la ciudad estaba decidida a hacer valer su patronato sin ambages, por lo que, habiendo expirado el plazo concedido, decidió presentar pleito en el Consejo de Castilla el 15 de junio ${ }^{112}$ : junto al amparo en sus derechos, exigía el cumplimiento de lo pactado o la expulsión de los frailes, subrayando el descrédito que para la devoción y las limosnas significaría un conflicto abierto. La reacción de los conventuales, cada vez más afectados en sus intereses por la ausencia de la imagen del santuario, fue acudir ante el ordinario diocesano, del cual obtuvieron despacho -comunicado a la ciudad el 4 de septiembre- para que en el primer festivo siguiente se devolviese la imagen al convento en la forma acostumbrada ${ }^{113}$. La ciudad recurrió el mandato del gobernador eclesiástico, lo que produjo la suspensión de su aplicación y la inhibición del ordinario por la litispendencia en el Consejo ${ }^{114}$.

109. Diferentes instrumentos... [1768]: 61-68 y 74.

110. Ibid.: 61-68. «Y perciban [dichos comisarios] las limosnas, que la devoción de los Fieles, assí vecinos, como forasteros, tan copiosamente suele tributar» (Ibid.: 62).

111. El 20 de marzo habrían registrado ante notario una escritura de protesta (Diferentes instrumentos... [1768]: 100) que dijeron haber manifestado en el propio acto de la firma de las capitulaciones (Ibid.: 94), cuatro días más tarde.

112. Ibid:: 85. El provincial había escrito días antes proponiendo algunos remedios para sosegar los ánimos (AHMV, AACC, 9-VI-1756).

113. Diferentes instrumentos... [1768]: 94. AHMV, AACC, 04-IX-1756, AHMV, 13/17.

114. Diferentes instrumentos... [1768]: 101. 
Se da la llamativa circunstancia de que el entonces gobernador del Consejo de Castilla no era otro que D. Diego de Roxas Contreras, titular a la sazón de la mitra de Cartagena. En cuanto a los agustinos, se mostraron parte en los autos el 5 de octubre, al tiempo que remitían un escrito al ayuntamiento en el que exponían sus razones. Por supuesto, presentaban su propia visión de los hechos, exactamente en los antípodas de la del ayuntamiento ${ }^{115}$. En cuanto al fondo de la cuestión, afirmaban no disputar en ningún momento el patronato municipal, pero lo reducían a lo puramente honorífico, y en su propia defensa alegaban la posesión quieta y pacífica en que habían estado del santuario desde el siglo XVI. Lógicamente, insistían en los inconvenientes que se derivaban de la ausencia de la Virgen de su casa natural ${ }^{116}$, y en consecuencia, pedían que se separase la cuestión del reintegro de la imagen (que debía hacerse ante omnia) de la de la disputa sobre el contenido y alcance del patronato (a resolver por la vía litigiosa) ${ }^{117}$.

Las opciones de los agustinos, sin embargo, eran muy escasas. La más evidente consistía en intentar demorar la aprobación por el provincial de la escritura pactada hasta que se resolviese el litigio: de hecho, a mediados de septiembre y finales de noviembre de 1756 -a instancias de la ciudad- el Consejo apremió a los conventuales para lograr la ratificación ${ }^{118}$, sin resultado. A esas alturas, el alargamiento del conflicto había tensado mucho los ánimos y no beneficiaba a ninguna de las partes, con la habitual combinación de elementos económicos y sobrenaturales. Se era consciente, por supuesto,

115. Según los agustinos, la ciudad había hecho donación «pura, mera y revocable» (Diferentes instrumentos... [1768]: 91), y «no se reservó otra cosa que el Patronato, que consiste en lo honorífico, y arreglado a la disposición de derecho» (Ibid.: 92). Por otra parte, la renuncia hecha en 1542 no era conforme a las constituciones de la orden, y por tanto, habría quedado subsistente su derecho sobre el santuario. En cuanto a los agustinos valencianos, eran conceptuados consecuentemente como intrusos, y habrían sido ellos los que se introdujeron con mano armada siendo expulsados con auxilio de la Real Justicia. Los murcianos se instalaron lógicamente bajo las condiciones del primer establecimiento, sin que la ciudad les hubiera pedido nunca lo que ahora les pedía. En consecuencia, defendían la nulidad de la escritura de 24 de marzo de 1756. Tampoco habría sido cierto que se les comunicara por la ciudad la suspensión de la rogativa ni que se trajera indecentemente a la virgen (Ibid.: 92-93).

116. Ibid.: 90-95.

117. Ibid.: 95.

118. Ibid.: 75. Madrid, 17-IX-1756. 
de que el desencadenamiento de largos pleitos iba en detrimento del «culto de su soberana Imagen, y las limosnas» de los fieles ${ }^{119}$; pero podemos imaginar también el modo en que el enfrentamiento abierto estaría dando pábulo a todo tipo de interpretaciones -incluidas las ultraterrenas- entre la mayoría de la población, en un año en el que había hecho su aparición una de las peores plagas de langosta del siglo ${ }^{120}$. A finales de diciembre, la ciudad hacía constar que las limosnas estaban efectivamente cayendo y que el gasto que suponía el mantenimiento del culto a cargo de los propios municipales se estaba haciendo insoportable, máxime teniendo en cuenta que los gastos derivados de los trabajos de extinción de la langosta estaban consumiendo la mayor parte de los recursos ${ }^{121}$. De modo que, como medida de ahorro se obtuvo autorización del Consejo para colocar interinamente la imagen en el convento de San Francisco de la ciudad, pensando en evitar los gastos de la venidera romería de marzo ${ }^{122}$; con esto, evidentemente la ciudad mantenía la presión, amagando con ceder la imagen a otra orden religiosa, cuestión sobre la que llegó a deliberarse en el cabildo municipal ${ }^{123}$, aunque finalmente, cercano ya el final favorable del pleito, se decidió no llevar a efecto la medida ${ }^{124}$.

Con todo, aún pasaron unos meses antes de la resolución definitiva del asunto. El 21 de mayo de 1757 el Consejo prohibió nuevos pedimentos ${ }^{125} \mathrm{y}$ sentenció por Real Provisión de 17 de septiembre (firmada también por D. Diego de Roxas) ${ }^{126}$. El fallo, como era previsible, resultó plenamente favorable para la ciudad: debía cumplirse en su integridad la escritura de 24 de marzo del año anterior, y respecto del convento, los frailes no tenían «más derecho, que el de habitarle, y ocuparle, mientras no faltasen a lo capitulado» ${ }^{127}$. Lo cierto es que el asunto ya se había resuelto por la vía de los hechos: el 13 de julio de 1757 , la comunidad monástica se obligaba rigurosamente a la

\section{Ibid.: 88.}

120. La plaga fue detectada en Villena el 10 de julio de 1756. MAS GALVAÑ, 129 (2012): 53-57.

121. Diferentes instrumentos... [1768]: 78.

122. Ibid.: 79. 15-XII-1756. Auto del Consejo de 5-II-1757.

123. Ibid.: 81.

124. Ibid.: 84-85. AHMV, 13/14.

125. Diferentes instrumentos... [1768]: 102. SOLER GARCía, 2009: [378].

126. GARCía LuJÁN, 1988: 67-68.

127. Diferentes instrumentos... [1768]: 106. AHMV, 13/18, 13/19, 13/20, 13/21. 
Devociones, conflictividad y clima. Los santuarios de Nuestra Señora de las Virtudes (Villena) y San Cayetano (Crevillent) durante la Edad Moderna

observancia de los capítulos acordados con la ciudad ${ }^{128}$, y el 16 de agosto la concordia había sido firmada por el superior y definidores de la provincia de Andalucía, en el convento de San Agustín de Cádiz ${ }^{129}$. Los agustinos permanecieron en el santuario hasta la ley de exclaustración de $1835^{130}$.

\section{El santuario de San Cayetano en Crevillent}

\subsection{Fundación y demolición de la primera ermita y construcción de la segunda}

Este santuario -hoy sin culto- fue fundado hacia 1673 por los duques de Arcos, entonces titulares del Marquesado de Elche y muy vinculados a la devoción teatina, en una dehesa señorial situada en la sierra de Crevillent ${ }^{131}$. La devoción al santo, canonizado dos años antes, se difundió rápidamente al tiempo que se extendía su fama milagrera ${ }^{132}$. Como es natural, el momento culminante lo marcaba la romería que se celebraba durante tres días (entre el 6 y el 8 de agosto ${ }^{133}$ ), con la suficiente afluencia de gentes del Marquesado y la Vega Baja ${ }^{134}$ como para hacer necesaria la presencia de empleados de

128. Diferentes instrumentos... [1768]: 104.

129. Ibid.: 104-105. AHMV, 13/22, 13/23, 13/24.

130. GARCía LuJÁN, 1988: 91-94. A finales de 1760 tuvo lugar un enfrentamiento entre el corregidor y el ayuntamiento, que se falló también favorablemente a la ciudad. Al tratarse de rogativas, se describe en el punto 4 de este trabajo.

131. La fecha fue propuesta en 1936 por el entonces párroco de Crevillent (MAS MAS, 2 (1936): 12) y es perfectamente congruente con diversos elementos cronológicos que hemos localizado por nuestra parte; igualmente, con los sondeos arqueológicos recientemente efectuados. Como en el caso de Las Virtudes, en el lugar existe un manantial permanente. La fuente documental más antigua en que se menciona la ermita data de 1693 (Archivo Municipal Elche -en adelante AME-, H/29-3, Carta de D. Carlos Caro Maza de Lizana al duque sobre la quema ocurrida en la dehesa de San Cayetano en Crevillente, Elche, 24-V-1693).

132. Como ocurre en tantos otros lugares, desde 1676 el nombre del santo se generaliza de forma imparable entre los varones bautizados en Crevillent.

133. El patrón de Crevillent, en conmemoración de la expulsión de los moriscos -que tuvo lugar el día de su festividad de 1609- es San Francisco de Asís. Sin embargo, la nueva devoción presentaba claras ventajas: se trata de un santo de verano, y además su día precede en una semana al ciclo festivo de la capital del Marquesado, Elche.

134. Estas procedencias están plenamente acreditadas en toda la documentación. Por otro lado, según noticia verbal comunicada por el arqueólogo David López -encargado de 
Devociones, conflictividad y clima. Los santuarios de Nuestra Señora de las Virtudes (Villena) y San Cayetano (Crevillent) durante la Edad Moderna

la real justicia ${ }^{135}$. La documentación manejada aporta igualmente diversas descripciones, todas coincidentes y de gran interés etnológico, tanto de la fiesta como incluso de la disposición del santuario y de los lugares donde se instalaban los feriantes que acudían al lugar ${ }^{136}$.

Habitualmente, el culto era servido por un presbítero capellán designado por la señoría, en ocasiones ayudado -aunque no siempre, por no tener señalada dotación económica- por un hermano lego, que sería en realidad el único residente fijo en el santuario ${ }^{137}$. Durante este periodo, la ermita estuvo siempre bajo el exclusivo patronazgo y cuidado de la casa de Arcos, cuyas armas estaban fijadas en la puerta, sin que nos hayan llegado noticias de especial conflictividad relacionada con el ejercicio del patronato. Eso sí, fue incluido en las visitas pastorales de los obispos oriolanos al menos desde la que tuvo lugar en $1732^{138}$.

Una combinación de factores llevó a la demolición y cierre de este primer santuario. No faltaron las consabidas quejas sobre los excesos morales que se cometían en el lugar, pero en el fondo del asunto se encontraba sin duda la necesidad de incorporar el producto de las cuantiosas limosnas que producía el santo a la construcción del nuevo templo parroquial crevillentino y a la dotación del clero parroquial, impulsada por el propio obispo de la diócesis, D. José Tormo y Juliá139. A ello debe sumarse el progresivo desinterés de los titulares del marquesado, máxime habiendo sido la ermita uno de los escenarios del importante motín antiseñorial de $1766^{140}$. Así pues, de común acuerdo

las recientes actuaciones efectuadas en el lugar- se ha identificado una proporción notable de piezas cerámicas procedentes de un taller coetáneo de Hellín.

135. Archivo Diputación Provincial Alicante, 873, varios recibos correspondientes a 1760 y 1761 .

136. Tanto MontesinOS, 1795 , como los testimonios del expediente abierto en 1815 describen, sin demasiadas diferencias, los actos que se celebraban, que junto a la misa y sermón, incluían procesión y porrat. Las tiendas de feria se ubicaban a la bajada del portichuelo que da acceso a la ermita.

137. MARTínEZ ESPAÑOL, 77 (2014): 258.

138. Archivo Histórico Diocesano Orihuela, $2 .^{a}$ visita del Ilmo. Sr. Flores: $218 \mathrm{v}$.

139. AME, H/29-7, Real Cédula de S. M. en que se sirvió aprobar la Concordia otorgada entre el Ilmo. y Rvmo. Sr. Don Joseph Tormo, obispo de Orihuela, y el Excmo. Sr. D. Antonio Ponce de León Spínola de la Cerda [...] duque de Arcos, 2-V-1771, Murcia, Felipe Teruel.

140. MAS GALVAÑ (2003): 1-13. La documentación sobre el motín de 1766 en Crevillent en AHN, Consejos, 22625. 
entre obispo y señor, y con el apoyo del clero parroquial y el ayuntamiento (temeroso, no obstante, de que se ocasionase algún tumulto estando aún muy reciente el anterior), en 1770 se procedió a la demolición y traslado de la imagen y el culto a la parroquia de Crevillent. Del producto de las limosnas del santo, se dispuso que en adelante se destinasen 80 libras anuales para la dotación de la masa de horas canónicas, y el sobrante quedara aplicado a la fábrica del nuevo templo ${ }^{141}$.

Sin embargo, a la muerte de Tormo -ocurrida en 1791- se había creado en la villa un claro estado de opinión favorable al retorno del santo a la sierra, que fue capitalizado por una familia, la de los Ardid, cuyo miembro más descollante fue el presbítero D. Cayetano Ardid y Mas (1736-1812). De acuerdo con un plan claramente trazado, mosén Ardid adquirió en mayo de 1791 los terrenos de la antigua ermita ${ }^{142}$ y solicitó al gobernador de la diócesis permiso para levantar una nueva ${ }^{143}$. Conseguido esto, obtuvo el apoyo municipal y del señor jurisdiccional (que en ningún momento hizo valer su antiguo patronazgo), para trasladar la imagen del santo a la ermita. Mediante decreto de 29 de diciembre de 1791, el ordinario diocesano accedió a la petición ${ }^{144}$ (a condición de que Ardid otorgase escritura de cesión de la ermita a la imagen), explicitando claramente que dicha autorización tenía carácter de «por ahora», sin perjuicio del destino dado por el ordinario a las limosnas y ofrendas recolectadas, y sin cesión de la potestad de nombramiento de capellán de la ermita. La donación fue aceptada por el cura, ante escribano y testigos, y se tomó razón de ella en el oficio de hipotecas de Elche ${ }^{145}$. Pese a la claridad de estos actos jurídicos, la escritura de cesión sería releída, interpretada y retorcida hasta extremos sorprendentes en los posteriores pleitos; llegado el momento, el propio Ardid -de modo en absoluto creíble- declaró que se le forzó «con violencia» a otorgarla (para «evitar un tumulto» ${ }^{146}$ ). El traslado a la sierra tuvo lugar el 5 de enero de 1792, con acompañamiento de las autoridades

141. AME, H/29-7, doc. cit.

142. Aunque la documentación en ningún momento lo precisa, debe entenderse que no se trató del enfranquecimiento, sino de la adquisición del dominio útil.

143. AHN, Consejos, 23.187, El cura y clero...,1815: 2v-3v.

144. Ibid.: $5 \mathrm{v}-7$.

145. Ibid.: 7v-10v.

146. Ibid., pieza (en adelante, pa.) 1. ${ }^{\mathrm{a}}$, numeración (en adelante, num.) 2. ${ }^{\mathrm{a}}$ : 119v. 
civiles y eclesiásticas y de numeroso público ${ }^{147}$. Bajo esta brillante fachada se escondían tensiones: pese a la insistencia interesada de Ardid en ser el primero en celebrar misa, fue el cura párroco quien lo hizo «con el objeto solo de acreditar desde luego con estos primeros actos su indubitable facultad y derecho privativo que como tal cura le competía» ${ }^{148}$. Acto seguido, dicho párroco nombró a Ardid capellán y administrador de las limosnas «con la prevención de deber estar subordinado en todo lo concerniente a la devoción del santo, sus ofrendas, misas y demás [...] al referido cura» ${ }^{149}$.

\subsection{Los pleitos por las limosnas y la capellanía hasta 1808}

Los primeros años del nuevo santuario transcurrieron sin incidentes notables. Pero ya en 1799 se produjo un primer problema con el reparto de las limosnas, cuando D. Cayetano impidió que el cura procediese a cobrarlo, lo que motivó una primera intervención del ordinario. El mismo problema volvería a repetirse en 1801, al negarse Ardid al pago de las 80 libras anuales, respondiendo al clero que no pensaba hacerlo «y así que acudieran donde quisiesen ${ }^{150}$. La cuestión provocó una discusión entre los miembros de la corporación eclesiástica que evidenció la existencia de profundas divisiones y llevó al inicio de un primer pleito contra D. Cayetano, al haber recurrido este ante el tribunal eclesiástico ${ }^{151}$.

Así las cosas, se configuró un frente de oposición a Ardid, con el objetivo de desalojarle de la capellanía interina y de cortar su acceso a las limosnas del santo. Su cabeza visible fue otro presbítero local, D. Cayetano Alzamora ${ }^{152}$, impulsado por diversos familiares: el racionero y antiguo fiscal eclesiástico Dr. D. José Mas; dos de los alcaldes ordinarios en diversos años, Salvador Ramos y Andrés Sanchis; y el notario del ayuntamiento y de la curia eclesiástica, Francisco Candela ${ }^{153}$. La estrategia de Alzamora apuntó -merced a

147. MONTESINOS, 1795: 150.

148. AHN, Consejos, 23.187, El cura y clero..., pa. 1. ${ }^{\mathrm{a}}$, num. 2. ${ }^{\mathrm{a}}$ : 174v.

149. Ibid.

150. APBC, Acuerdos parroquiales: 64-66.

151. Ibid.: 60, 67-68v. AHN, Consejos, 23.187, El cura y clero..., pa. 1. a, num. 2. a. 322v. y ss. 152. Aunque no hemos podido identificar plenamente la partida de bautismo, está claro que se trataba de un individuo mucho más joven que Ardid, quizá recién ordenado.

153. AHN, Consejos, 23.187, El cura y clero..., pa. 1. ${ }^{a}$, num. 2. ${ }^{\text {a. }}$ : 254v-255. 
la influencia que tenía en la curia el Dr. Mas- a solicitar del obispo Cebrián (en el mismo año 1801) que le nombrase capellán titulado, alegando las dificultades de salud del ya sexagenario Ardid, que le impedían asistir al culto y mantenían en la incuria y el descuido tanto la ermita como la administración de las limosnas. Su petición dividió aún más al clero parroquial ${ }^{154}$. Ardid, por su parte, intentó también que el obispo le confirmase oficialmente como capellán (ofreciendo dotar la capellanía con sus bienes), pero dado que el interlocutor designado fue Mas ${ }^{155}$, la negociación no solo no llegó a ningún puerto, sino que finalmente, el 20 de julio de $1804^{156}$ el obispo resolvió el nombramiento en favor de Alzamora, con otorgamiento de título y de plenos derechos ${ }^{157}$. Tres días más tarde, se le daba posesión del santuario ${ }^{158}$.

La reacción de Ardid no se hizo esperar, dando lugar a una cascada de litigios:

1. Pleito en la curia eclesiástica de Orihuela. Ardid acudió a este tribunal pidiendo el reintegro en el derecho de patronato y posesión de la ermita, y la condena de Alzamora a la restitución de limosnas, ofrendas, daños y perjuicios ${ }^{159}$. Nunca llegó a sentenciarse.

2. Simultáneamente al inicio del anterior, y con motivo de haber recibido un hermano de Ardid unas ofrendas al santo, Alzamora acudió ante la justicia de Crevillent quejándose por estar siendo perturbado en la posesión de la capellanía y administración de limosnas. Se le amparó en los mismos términos en que se hallaba por el título del obispo ${ }^{160}$. Ante la denegación de la apelación de Ardid por extemporánea, este presentó recurso en la Audiencia de Valencia, donde se le admitió en 18 de junio de 1805, revocándose las providencias del alcalde mayor, admitiendo las apelaciones, y reteniendo los autos en la sala ${ }^{161}$.

154. APBC, Acuerdos parroquiales: $74 \mathrm{v}-78$.

155. AHN, Consejos, 23.187, El cura y clero..., pa. 1. ${ }^{\text {a }}$, num. 2. a. 169.

156. Ibid., pa. 1. ${ }^{\mathrm{a}}$, num. 2. ${ }^{\mathrm{a}}$ : $3 \mathrm{v}$.

157. Ibid., pa. 1. ${ }^{\mathrm{a}}$, num. 2. : $^{\text {15 } 159-162 .}$

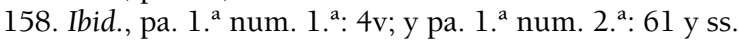

159. Ibid., pa. 1. ${ }^{a}$ num. 2. ${ }^{a}: 71-84$ y 90.

160. Ibid., pa. $1 .^{a}$ num. $1 .^{a}: 1$.

161. Ibid., pa. 1. ${ }^{\text {n }}$ num. 2. ${ }^{\text {a. }} 42$. 
3. Se había dado así un paso clave en el rumbo de los acontecimientos. El 3 de septiembre de 1805 la Audiencia amparó a Ardid entendiendo que no solo era propietario de la ermita, sino que estaba en plena posesión del título de capellán y en el derecho de percibir y administrar las ofrendas ${ }^{162}$. Esta decisión vino a completarse con otra aún más radical: como quiera que Alzamora había hecho uso del recurso más lógico a su alcance (solicitar al ordinario diocesano la devolución de la imagen a la parroquia), Ardid acudió a la Audiencia con el fin de evitarlo, y esta, considerando que se trataba de un asunto propio de la jurisdicción real y que no debía inmiscuirse el ordinario eclesiástico ni directa ni indirectamente, dispuso -el 1. ${ }^{\circ}$ de octubre de 1805-que en caso de presentarse orden u oficio emanados del tribunal episcopal para retirar la imagen de la ermita, o cualquier otra relativa al título de capellán o al santuario, las justicias civiles no las cumplimentasen ni diesen auxilio alguno, con obligación de comunicarlo a la Audiencia, bajo multa de 200 libras $^{163}$.

4. La actuación del escribano Francisco Candela, en todo momento relacionado con el «partido» de Alzamora, terminó motivando la apertura de un proceso separado. El motivo fue el incumplimiento por su parte de la orden de $1 .^{\circ}$ de octubre de 1805, pues se presentó en la ermita el día 13 del mismo mes acompañado de siete embozados (alguno incurso en causa criminal) e interrumpió la celebración de la misa para comunicar un decreto del provisor; también habría intentado Candela encarcelar a José Ardid, y al propio D. Cayetano le notificó violentamente dicho decreto en la plaza del pueblo ante numerosa gente, provocándole un ataque apoplético. Atendiendo a la petición de Ardid, la Audiencia ordenó a Candela que se presentase en Valencia a disposición de la sala, que le mandó guardar por cárcel la ciudad y sus arrabales ${ }^{164}$.

162. Ibid., pa. 1. ${ }^{a}$ num. 2. ${ }^{\text {a. }} 246$.

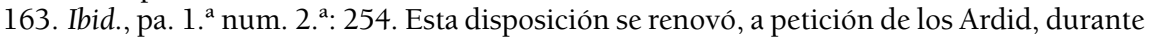
los años 1812 y 1813.

164. Ibid., pa. 2.': 23, 94. 
La jurisdicción eclesiástica no permaneció inmóvil ante esta cadena de acontecimientos, de modo que el provisor diocesano pidió a la Audiencia la revocación y anulación de todos los procedimientos relativos a la ermita, reclamando el conocimiento de la causa; en caso contrario, pasaría a formarse la competencia entre ambos tribunales ${ }^{165}$. Sin moverse un ápice de sus posiciones, la Audiencia optó por esta última vía, razón por la cual -al formalizarla- el provisor pidió que la cuestión litigiosa se extendiese a la facultad episcopal de nombrar capellán de la ermita así como a la protección del escribano Candela, que habría actuado en calidad de notario eclesiástico ${ }^{166}$. La competencia terminaría por elevarse hasta el rey, al decidir la Audiencia (en diciembre de 1806) su remisión por la vía reservada de Gracia y Justicia ${ }^{167}$, no sin que en los meses anteriores los fiscales de la curia oriolana y de la Audiencia cruzasen una serie de alegatos durísimos, con fuertes descalificaciones del oponente.

Sin embargo, en Madrid el asunto pronto comenzó a tomar otro cariz. Remitido al Consejo de Castilla, la propuesta de consulta al rey hecha por el fiscal (11 de marzo de 1807) indicaba que correspondía al ordinario de Orihuela el conocimiento de la causa sobre la capellanía; por el contrario, el conocimiento del expediente contra Candela tocaría a la Audiencia, pero en atención a lo que este había sufrido y a los gastos que se le habían originado, convenía sobreseer el caso ${ }^{168}$. Así quedaron las cosas cuando estalló la Guerra de Independencia.

\subsection{Los sucesos de 1815 y la resolución del Consejo}

Aún en pleno conflicto bélico, la muerte se llevó a Ardid el 10 de febrero de 1812. Protegido siempre por la Audiencia valenciana, el incombustible clérigo no había dudado en legar el santuario a sus hermanos Celedonio y José; en cumplimiento de estas disposiciones testamentarias, se les dio posesión judicial $^{169}$. A partir de ese momento, ya no se trataba del problema causado por un clérigo, sino que dos legos habían pasado a poseer y administrar el santuario.

165. Ibid., pa. 1. ${ }^{a}$ num. 2..$^{\text {a. }}$ 283-315 (en particular, 310v).

166. Ibid., pa. 1. ${ }^{a}$ num. 2. a. 374-394.

167. Ibid., pa. 1. ${ }^{\mathrm{a}}$ num. 2. ${ }^{\text {a. }} 404$.

168. Ibid., pa. 2.: $162 \mathrm{v}$.

169. Ibid., ramo 1. : $28 \mathrm{v}$. 
Ante este hecho, y una vez terminada la guerra, iba a cobrar fuerza la ofensiva del clero (ahora unánime) para recuperar el control sobre la devoción y las limosnas; todo hay que decirlo, el comportamiento de Celedonio, José, y sus hijos (dando lugar a notorios escándalos y administrando patrimonialmente las limosnas) vino a dar alas a sus oponentes. Las sequías de 1814 y 1815 facilitaron -como veremos- unos infructuosos intentos para bajar la imagen en rogativa al pueblo; no fiándose los Ardid -en 1814 volvió a ser alcalde primero el mismo familiar de Alzamora que ocupó el cargo en 1805- acudieron a la Audiencia, que les amparó de nuevo ordenando que no se innovase mientras la competencia pendiente en el Consejo no se resolviese ${ }^{170}$. Unos intentos del alcalde (que también poseía casa en el santuario) por comprarles sus tierras fracasaron, de modo que se pasó al conflicto abierto. En un primer momento, el provisor ordenó poner en posesión al cura y clero parroquial, lo que llevó a la detención de José Ardid; la Audiencia lo puso en libertad de inmediato. De modo que a lo más que se alcanzó en 1814 fue a nombrar un depositario de las limosnas, de común acuerdo entre el clero y los hermanos, lo que puso de manifiesto que solo en los días de la romería -pese al descenso en las limosnas por la presencia de malhechores en la zona- la recaudación rondó los 15.000 reales (unas 1.000 libras), pudiendo estimarse la recaudación anual en el doble de esta cantidad.

El clímax del conflicto se alcanzó durante los días de la romería de 1815. Parece ser que, desde varios meses antes, y ante el miedo a que les pudiesen privar de la imagen, los Ardid la habían sacado de la ermita y escondido en alguna de las cuevas de la sierra. El caso es que en la madrugada del domingo 6 de agosto, con miles de personas congregadas en el santuario en compañía del clero parroquial, las puertas de la ermita permanecían cerradas. Pronto llegó aviso de que la imagen había sido encontrada -muy deteriorada- en un higueral a media legua de distancia, transportada en un jumento y envuelta en una sábana y un colchón; José Ardid, su hijo y un hijo de Celedonio la acompañaban, en un intento bastante descabellado de acercarla a la ermita

170. Existen en el expediente múltiples descripciones de los sucesos que se describen a continuación, especialmente los de agosto de 1815. Por su carácter sintético, citaremos la del provisor D. Pedro Goyeneche, de 23 de dicho mes (AHN, Consejos, 23.187, El cura y clero...: 21-26v). 
sin ser vistos. El párroco no desperdició la ocasión: comisionó a dos sacerdotes que la recogieron y la condujeron a la parroquia. Como quiera que la Audiencia siguió protegiendo en todo momento a los Ardid con sus órdenes de no innovar, el asunto aún daría lugar a algunas escenas francamente llamativas, como la de la aparición en Crevillent, en una noche de septiembre, del alcalde mayor de Elche acompañado de tropa que -a bayoneta calada-, sacó expeditivamente a los regidores de sus domicilios, los condujo a las casas consistoriales y allí les despojó de la jurisdicción, asumiéndola él por orden de la Audiencia. Los interrogatorios que llevó a cabo de los testigos de los sucesos del 6 de agosto también fueron denunciados como coactivos ${ }^{171}$. Cabe destacar igualmente la reunión de notables crevillentinos que se celebró para identificar la imagen del santo, tras su «profanación» por los Ardid, donde se describe con todo detalle el pésimo estado en que se hallaba y las roturas que había sufrido ${ }^{172}$.

Al calor de estos sucesos, el provisor eclesiástico D. Pedro Goyeneche, representó directamente al rey el 25 de agosto $^{173}$. Tanto el clero local como el ayuntamiento avalaron por su parte la exposición de Goyeneche, quien terminó solicitando que se actuase como en 1770; es decir, que se procediese a la total demolición de la ermita y a la continuación del culto en la parroquia; en cuanto a las limosnas y ofrendas, proponía que quedasen al cuidado del clero y bajo la dirección del ordinario ${ }^{174}$. De entre los informes que solicitaría el Consejo de Castilla a raíz de esta petición, el más llamativo es el de la Audiencia de Valencia, la que (para poder recoger velas y adherirse sustancialmente a la propuesta) afirmaba -con evidente falsedad-que en la documentación de los pleitos no constaba la escritura de cesión hecha por Ardid. Todo ello, según la sala valenciana, había inducido al error de tratar la cuestión como si se tratase de un asunto de patronato laico, favoreciendo por tanto no solo a Ardid sino a sus legatarios ${ }^{175}$. Por otra parte, no terminaría el expediente sin que se remitiesen al Consejo sendas representaciones de dos

171. Ibid.: 68-71v. Debe tenerse en cuenta que esta actuación del alcalde mayor de Elche se produjo tras la abolición de las jurisdicciones señoriales.

172. Ibid.: 18-20v.

173. Ibid.: 21-26v.

174. Ibid.: 43-45.

175. Ibid.: 85-86v. 
poblaciones de la Vega Baja del Segura (Benejúzar y Cox), y una tercera, en nombre de «más de 800 vecinos» de Crevillent, solicitando la devolución del santo a la ermita ${ }^{176}$.

El fiscal se adhirió a la propuesta del ordinario diocesano. Sin embargo, el Consejo la matizó en su definitiva resolución de 10 de mayo de 1817. En primer lugar, se mandaba sobreseer en todos los procedimientos pendientes; en cuanto a la imagen y culto, debía permanecer en la parroquia, recaudándose e invirtiéndose las limosnas y ofrendas por un síndico nombrado por el cura y clero -de una parte-, y por el procurador síndico del ayuntamiento -de otra-, con obligación de rendir cuentas anualmente a la mitra; respecto de la demolición, se dejaba para ulterior decisión, una vez informase el prelado; finalmente, se efectuaba una leve reprensión al clero parroquial, destinada sin duda a salvar el honor de la Audiencia, por no haber obedecido aquel con exactitud las determinaciones de esta ${ }^{177}$. En consecuencia, la decisión final suponía el reconocimiento pleno de la interpretación jurídica presentada desde el principio por el ordinario eclesiástico, basada en la plena validez de la escritura de cesión de 1792 y de sus términos: lejos de tratarse del oratorio particular de un patrono laico, el santuario había sido siempre un oratorio público, con una imagen cuya propiedad y disposición pertenecía a la parroquia y al obispo.

Terminaban así los complejos expedientes judiciales relacionados con la ermita. No así, como veremos para concluir, su azarosa historia.

\section{El trasfondo climático}

No es necesario insistir en la enorme exposición de la agricultura tradicional a los ciclos y eventos climáticos. A mayor abundamiento, la totalidad del periodo estudiado aquí se halla afectado por las condiciones de la denominada «Pequeña Edad del Hielo», que también dejó sentir sus efectos en la fachada mediterránea peninsular, con diversas pulsaciones como las representadas

176. Ibid.: 123-127v.

177. Ibid.: sin foliar [posterior al f. 133]. 
por el «mínimo de Maunder», la «anomalía Maldà», o el «año sin verano» de $1816^{178}$.

En este sentido, el papel de los intercesores se hace especialmente evidente ante los frecuentes episodios de sequía. En el caso de Villena, ya hemos indicado que el papel asignado a la Virgen en tales coyunturas se encuentra documentado al menos desde $1551^{179}$; también los sucesos de 1756 se desencadenaron como consecuencia de la organización de unas rogativas. Y en efecto, las actas municipales villenenses reflejan y detallan la organización de gran cantidad de este tipo de ceremonias. A la espera de futuros análisis exhaustivos del conjunto de esta documentación, hemos revisado los fondos correspondientes a la denominada «anomalía Maldà» (1760-1800). Teniendo en cuenta que han desaparecido los libros correspondientes al quinquenio 1772-1776, la serie estaría integrada por un total de 36 años. De ellos, en al menos 22 se habrían producido rogativas como consecuencia de la sequía ${ }^{180}$. Vinculadas a los ciclos agrícolas, habitualmente se organizaban a finales de invierno o comienzos de la primavera, impetrando el beneficio del agua para ayudar a que madurase la próxima cosecha; sin embargo, aunque con menos frecuencia, también podía ocurrir que tuvieran lugar durante el otoño, para la siembra ${ }^{181}$. En cuatro de los años indicados (1770, 1780, 1787 y 1788) se celebraron en ambos periodos. Estos datos vienen a confirmar la tendencia general observada en las áreas

178. Alberola Romá, 2014. Barriendos y Llasat, 61 (2003). Para el entorno próximo a los santuarios estudiados en este artículo, son de interés las recientes tesis de BUENO VERGARA, 2014 y García TORRES, 2015.

179. Diferentes instrumentos... [1768]: 14.

180. Se trata de los años 1760, 1764, 1766, 1767, 1770, 1777, 1778, 1779, 1780, 1781, 1783, 1786, 1787, 1788, 1789, 1790, 1791, 1794, 1795, 1796, 1798 y 1800. En algún otro caso debe haberse producido algún tipo de rogativa, pero la documentación no ofrece detalles suficientes para precisar la causa. Debe tenerse en cuenta que también se recurría a la Virgen de las Virtudes en circunstancias de salud (por las recurrentes situaciones de contagios de tercianas causadas por la laguna inmediata) o en otras situaciones excepcionales (como la plaga de langosta de 1756, o el giro adverso de la guerra contra la Convención en 1794). En algunos casos, como el de este último año, se combinaron los tres factores (sequía, contagio y guerra) para motivarla.

181. En los años 1770, 1778, 1780, 1786, 1787, 1788, 1794 y 1798. 
próximas, así como la recurrencia de las rogativas durante la «anomalía Maldà» ${ }^{182}$.

Como es sabido, la rogativa respondía a un detallado procedimiento, que implicaba a un conjunto de instituciones y podía suponer notables desembolsos $^{183}$. Consiguientemente, se procedía de los actos de culto más simples y económicos, a los más complejos y caros. Como ocurría de modo general, en el caso de Villena -si la sequía no era grave- el ayuntamiento podía requerir el inicio de plegarias en las dos parroquias y los otros conventos (franciscano y de trinitarias), generalmente invocando como intercesoras a las ánimas del Purgatorio ${ }^{184}$. Sin embargo, rara vez era suficiente: solo en cinco ocasiones descargó la lluvia antes de que fuese necesario dar pasos adicionales ${ }^{185}$. Lo que significa que en las restantes terminó recurriéndose a la Virgen de las Virtudes, que en el caso de Villena era además la intercesora de último recurso. En estos casos, reproduciendo el procedimiento común en todas partes, la iniciativa invariablemente era tomada por los labradores, que la trasladaban al concejo mediante un escrito solicitando la celebración de la rogativa; el resultado solía ser la decisión de traer a la Virgen a la ciudad, donde se la instalaba en la parroquial de Santiago y se le tributaba un novenario de misas y sermones. Pasados los nueve días, la imagen era devuelta al santuario, no sin antes sacarla en procesión general por las calles de la ciudad.

Determinados factores podían llevar a los labradores a pedir la ampliación de la permanencia en la ciudad, desde un novenario adicional hasta varios meses. En 1780, no solo se trajo a la Virgen para asegurar la recolección de la cosecha del trigo, sino que se atendió a las súplicas de los labradores y se la mantuvo hasta la recogida de la del panizo (maíz). Una decisión semejante se adoptó en 1781 y 1795. Sin embargo, no siempre la ciudad condescendía ante estas peticiones. Ante todo, estaba la cuestión del coste económico de las rogativas, tanto mayor cuanto más larga fuera la estancia de la imagen en la ciudad. El procedimiento habitual consistía en publicar la venida y abrir un periodo de aportación de limosnas, que se encargaba de recolectar el propio

182. Alberola, Bueno y García, 2016: 129, 132-143. García Torres, 2016: 161-165. Creus y SAZ, 23 (2005): 35-48.

183. Alberola, Bueno y García, 2016: 124, 129.

184. Así ocurre claramente en el año 1789.

185. En los años 1766, 1770, 1778, 1779 y 1790. 
ayuntamiento, pero si las circunstancias lo exigían podía optarse por otras vías. Así, en 1767, se solicitó autorización real para disponer de hasta 3.000 reales de los caudales de propios municipales ${ }^{186}$. Veinte años más tarde, ante la petición cursada por los labradores, la ciudad les pidió directamente que aportasen al menos la misma cantidad: sin demora, estos depositaron un total de 3.656 reales, y se celebró inmediatamente la rogativa ${ }^{187}$.

Estos equilibrios nunca resultaban fáciles. Podía ocurrir, como en 1789 , que se negase a los labradores la prolongación de la estancia de la Virgen hasta la recogida de la cosecha ${ }^{188}$; en otras situaciones, surgían disensiones en el seno de la corporación, como sucedió en 1787 ${ }^{189}$; y ciertamente, siempre existía el temor a un tumulto popular. Cuando en 1780 se decidió mantener a la Virgen en Villena, se indicaba que «el pueblo está conspirando para que así se haga ${ }^{190}$. Veinte años antes, en 1760 , se había producido un serio incidente en el propio santuario. En una situación de grave sequía, llevado de su deseo de ahorrar y no sin recelar del posible descontento, el ayuntamiento se personó en el santuario en lugar de trasladar la imagen al núcleo urbano. $\mathrm{Y}$, efectivamente, los temores de los regidores se vieron confirmados: tras el sermón, el pueblo se volvió hacia D. Francisco Cervera (en funciones de corregidor) «armando un gran alboroto donde por algunos momentos se creyó perdido, pidiendo la gente que se trajese la Virgen a Villena en rogativa, que es de la única manera que están convencidos que la Virgen les consolará en sus adversidades ${ }^{191}$. Viendo que el escándalo aumentaba y temiendo por su integridad, no tuvo Cervera más salida que avenirse a la petición: el concejo villenense acordó trasladar la imagen al pueblo el siguiente domingo. Como quiera que terminó por llover abundantemente, el pueblo se aquietó ${ }^{192}$, pero

186. AHMV, AACC, 23-III-1767.

187. AHMV, AACC, 29 y 31-III-1787. García Luján describe la aplicación de un mecanismo similar con motivo de la gran sequía de 1750 (GARCÍA LUJÁN, 1988: 69-70). También en 1803, al solicitar que la Virgen permaneciese en Villena hasta la siega, el ayuntamiento les exigió 1.000 reales en depósito para cubrir los gastos (GARCía LUJÁN, 1988: 77-78).

188. AHMV, AACC, 9-V-1789.

189. AHMV, AACC, 24-V-1787.

190. AHMV, AACC, 31-III-1780.

191. AHMV, AACC, 14-III-1760.

192. GARCíA LUJÁN, 1988: 73-74.

Revista de Historia Moderna, n. 35 (2017) (pp. 254-307) | ISSN-e: 1989-9823 | ISSN: 0212-5862 
inmediatamente se abrió un flanco inesperado. El corregidor, motu proprio, dio un auto en virtud del cual privaba a la ciudad del derecho de recaudar las limosnas para la rogativa, nombrando a los dos párrocos como recolectores y depositarios. La ciudad protestó de inmediato ante el Consejo de Castilla por lo que entendía un despojo de su derecho privativo. En su alegato, explicaba que habitualmente las limosnas cubrían de sobra el gasto de la función, pero en caso de que no fuese así, se suplía de los propios municipales. Ahora, el corregidor ordenaba que se destinasen las limosnas a otros fines, mientras que los gastos de cera, misas, sermones, pólvora y demás debían pagarse íntegramente de los propios. El Consejo falló enteramente a favor de la ciudad por la Real Provisión de 12 de noviembre de dicho año, que ordenaba el restablecimiento del sistema acostumbrado y el reintegro de las limosnas, con un serio apercibimiento al corregidor ${ }^{193}$.

No obstante, la crónica escasez de caudales de propios ${ }^{194}$, el control ejercido por la intendencia, e incluso el incremento de los costes económicos ${ }^{195}$, llevó en 1786 a optar por sacar la imagen procesionalmente, en el día de su festividad de septiembre y en demanda de lluvia, solo por la plazuela del convento, sin llevarla a la ciudad. En este caso, la idea había sido del corregidor, y parece que no halló más dificultad que la oposición del síndico personero, que debió entender que entre sus funciones se hallaba la de hacer sistemáticamente suyas las peticiones de rogativas planteadas por los labradores ${ }^{196}$. Añadiremos unas notas adicionales respecto de estas cuestiones por lo que se refiere al santuario villenense. Por una parte, a partir de los años de 1780 se hace patente el control de la intendencia de Murcia sobre los gastos de las rogativas, en la medida en que se financiaban con fondos de los propios: es el

193. Diferentes instrumentos... [1768]: 105-110. AHMV, 13/31.

194. MORENO NiEVES, 6-7 (1986-1987): 222. Los gastos religiosos fueron los que más crecieron en el periodo 1708-1766.

195. En 1792, a petición de personero, la ciudad decidió incrementar el presupuesto destinado a las fiestas locales, entre otras razones, por haberse encarecido mucho la cera, por la mucha concurrencia de pobres en las dos romerías al santuario, y por el considerable aumento del número de eclesiásticos a quienes se daba propina. El incremento de la partida fue autorizado por la intendencia (AHMV, AACC, 01/09/1792).

196. AHMV, AACC, 7-IX-1786. 
intendente quien decide la cantidad a extraer y su destino ${ }^{197}$. Por otra parte, cabe mencionar las lógicas y repetidas quejas de los conventuales (aunque ya nunca pasaron a mayores) cuando las permanencias de la Virgen fuera del santuario se extendían más de lo habitual, por la disminución en la afluencia al convento y, lógicamente, de las limosnas que percibían los religiosos ${ }^{198}$. No podemos dejar de anotar finalmente que -en ocasiones- la causa de tales demoras en el retorno fue el éxito de la rogativa, puesto que las lluvias que en este periodo venían con frecuencia a interrumpir abruptamente las sequías, convertían en impracticable el camino directo al convento (que atravesaba zonas inmediatas a la laguna) forzando, bien a utilizar un camino más largo, bien a retener la imagen en Villena ${ }^{199}$.

Por lo relativo a la ermita San Cayetano, ignoramos cuándo se asoció la capacidad de intervención sobre el clima a la devoción por el teatino en Crevillent. Aunque la ermita fue fundada en pleno «mínimo de Maunder», carecemos de noticias concretas para ese primer periodo. Sin precisar fechas, Montesinos apuntaba -en realidad, haciéndose eco de una opinión común en todas partes- que entre los vecinos de los pueblos inmediatos se decía que la campana de la ermita, amén de compartir la virtud de las de iglesia contra «toda mala infección de los aires», la tenía «especial (luego que se toca) contra las malas nubes, como lo demuestra la misma experiencia» ${ }^{200}$.

Pero la idea de que la protección de San Cayetano resultaba efectiva contra las adversidades climáticas arraigó especialmente durante la «anomalía Maldà». De hecho, el éxito de la operación de Ardid se apoyó en la utilización (o creación) de un estado de opinión muy concreto: desde que el santo había sido trasladado a Crevillent, las cosechas estaban siendo especialmente malas. Y eso podía ser causa de alteraciones populares, siempre tan temidas por las autoridades locales. En los informes municipales sobre la demolición de la primera ermita pesa muy claramente ese temor, teniendo presente la

197. AHMV, AACC, 18-V-1786 y 8-III-1787. El único gasto autorizado a cargar sobre estos fondos fue el de la cera.

198. Valga como ejemplo la carta remitida por el prior al ayuntamiento, vista en el cabildo del 14-X-1780. La Virgen estaba en Villena probablemente desde marzo.

199. Así ocurrió en 1794 (AHMV, AACC, 22-III), 1795 (AHMV, AACC, 4-III) y 1796 (AHMV, AACC, 19 y 30-III).

200. MONTESINOS, 1795: 154. 
inmediatez de los graves sucesos de 1766. Pero es en la petición de traslación cursada por el ayuntamiento crevillentino al ordinario diocesano en 1791, donde clima y tumultos aparecen claramente relacionados:

Los vecinos todos de [Crevillent], en quienes como es notorio reside una cordial devoción al glorioso San Cayetano, miran con displicencia el poco culto y veneración que se tributan a su imagen desde que fue trasladada de la ermita, que quedó derruida, a la parroquial Iglesia, y aun han formado la aprensión de que las cosechas de sus campos han sido desgraciadas desde aquel contingente, por manera que continuamente anhelan retornarle a su antigua casa ${ }^{201}$.

No sorprende, así pues, que -en su decreto de autorización- el vicario general diocesano reflejase una situación que había alcanzando un alto grado de crispación, derivando en conatos violentos:

habiendo tenido noticia por los referidos alcaldes que, si no se condescendiese a la devoción del pueblo, hay peligro de que se amotinen, como ya lo han intentado algunas veces, queriendo quemar las casas de algunos sujetos, solo por una leve presunción de que eran contrarios a la translación del Santo a su antiguo lugar, por estar persuadidos que la falta de cosechas que padecen, procede de que antes en el monte era muy venerado su patrono San Cayetano ${ }^{202}$.

Volviendo al texto de Montesinos, sus informaciones resultan de gran interés cuando actúa como testigo de su propio tiempo, bien dando noticias de sucesos, bien transmitiendo tradiciones que oía contar. En el caso que nos ocupa, hace relación de un total de trece milagros atribuidos al santo en Crevillent. Los doce primeros los sitúa con anterioridad a 1709 y en todos los casos se trataba de sanaciones; en cambio, el gramático oriolano fue coetáneo del último milagro («sobre remediar el santo con agua»), ocurrido en 1799. Su relato no solo ofrece una prolija descripción de la rogativa que se llevó a cabo en marzo de ese año, sino de las solemnes celebraciones civiles y religiosas con las que se honró al santo a principios de junio para devolverlo a la ermita ${ }^{203}$. D. Cayetano Ardid -calificado por Montesinos como «sacerdote ejemplar»aún permitía estos traslados, consciente de lo mucho que podían beneficiarle.

201. AHN, Consejos, 23.187, El cura y clero...: 4-5v.

202. Ibid.: $5 \mathrm{v}-7$.

203. MONTESINOS, 1795: 164-170. 
Una breve, pero contundente cita, aclara el trasfondo económico: en una de las juntas del clero parroquial, el presbítero D. Manuel Quesada afirmaba que en «ningún año habían sido tan crecidas las ofrendas sin embargo de ser un año estéril» ${ }^{204}$.

Más adelante, en los conflictos de 1814 y 1815 las cuestiones climáticas volvieron al primer plano. Y es que, antes de que se produjesen los sucesos del 6 de agosto de 1815, en los primeros meses de ambos años ayuntamiento y clero -a instancias de los labradores- habían intentado organizar rogativas para impetrar el agua del cielo. Conservamos la de 1814, copiada íntegramente en el libro de acuerdos de clero parroquial ${ }^{205}$. El documento, que lleva fecha de 19 de enero, no aporta novedad especial, más allá de enfatizar la "grande sequedad y notable falta de agua como actualmente se experimenta», añadiendo que en circunstancias anteriores similares se acordó el traslado de santo a la parroquia. El ayuntamiento se reunió el 20 del mismo mes, y acto seguido decretó la traslación, fijándola para el inmediato 23, para lo que se pasó recado al cura por medio del secretario municipal, quien de inmediato prometió auxiliar en todo.

Y en 1815, estando aún pendientes -como se ha referido- los diversos contenciosos judiciales, mediante auto de 15 de marzo el provisor Goyeneche no dudó en mandar que el cura y clero de Crevillent extrajeran la imagen de San Cayetano de la ermita y:

la trasladen, de acuerdo y en unión con la Justicia y Ayuntamiento de dicha Villa de Crevillente, a su iglesia parroquial en rogativa para satisfacer a los públicos religiosos votos de dicho pueblo; en cuyo templo permanezca con el culto que es debido, por ahora y hasta que cese la necesidad actual que se alega; y, concluida, se devuelva la imagen a dicho santuario ${ }^{206}$.

La respuesta de los Ardid fue en los dos años la misma: cerrar la ermita y ausentarse, con «burla» de ambas corporaciones y de las «piadosas intenciones» de los fieles: la Audiencia había autorizado las rogativas, pero solo

204. APBC, Acuerdos parroquiales : $74 \mathrm{v}-78$.

205. Ibid.: 109-109v., Memorial que los labradores de esta villa dirigieron al Ayuntamiento Constitucional sobre la traslación de la prodigiosa imagen de san Cayetano en forma de rogativa. En la vecina Elche no se celebraron rogativas en 1814, pero sí en 1815 (AME, b-422: 487).

206. AHN, Consejos, 23.187, El cura y clero...: 12-18v. 
si los Ardid prestaban su consentimiento al traslado (cosa que, obviamente, nunca hicieron).

No hay duda de que la sentencia recaída en el pleito en 1817 fue acatada, ni de que el clero parroquial se hizo cargo de mantener el culto en el templo crevillentino. Sin embargo, no había terminado aún la azarosa historia del santuario. De hecho, una noticia publicada en 1936 por el párroco local, magnífico conocedor de la historia de su iglesia, pero no confirmada por ninguna otra fuente, nos coloca al borde del realismo mágico: en enero de 1819, estando casi terminada la cúpula del nuevo templo, fue alcanzada y arrasada por un rayo... ${ }^{207}$ Cierto o no, era evidente que los ánimos no se habían calmado y que un amplio sector de la población deseaba volver a ver a San Cayetano en su ermita. Esto explica el nuevo motín popular con el que comenzó el Trienio Liberal en Crevillent. Tal como relató el entonces titular de la parroquia, la noche del 19 de marzo de 1820 se congregó una multitud en el pueblo, le exigieron las llaves de la iglesia y, viendo que se resistía, le manifestaron taxativamente: «Señor cura, el santo a la sierra». En evitación de males mayores, el rector les abrió la puerta del templo, los cabecillas colocaron la imagen del santo sobre unas andas, $\mathrm{y}$ «hombres, mujeres y niños con vivas y aclamaciones a dicho santo a voz en grito [...] en aquella hora que eran las diez de la noche poco más [...] se marcharon con ella con dirección hacia el monte» ${ }^{208}$. ¿Quién esperaba allí? Por supuesto, los hermanos Ardid, quienes en 1821 no tuvieron empacho en indicarle al presbítero que subió -comisionado por el clero local-a intentar cobrar las limosnas del santo, «que [allí] no había más amos que ellos» ${ }^{209}$. Aunque los eclesiásticos recurrieron a la justicia local, en esta ocasión el alcalde se desentendió por completo. En todo caso, se trata de las últimas noticias existentes sobre la presencia de la imagen en la ermita de la sierra. De la lectura de la documentación, se desprende que en 1826 la imagen de San Cayetano se hallaba de nuevo -y esta vez definitivamente- en el templo parroquial ${ }^{210}$.

207. MAS MAS (1936): 12.

208. APBC, Acuerdos parroquiales: 146v.

209. Ibid:: 150 .

210. La ermita quedó sin culto, y sus últimos restos han sido recientemente demolidos. Con fondos públicos, pero con utilidad aún desconocida, se ha construido un nuevo edificio, pésimo remedo del anterior. Debido al crecimiento demográfico de 


\section{Conclusiones}

Los dos santuarios estudiados presentan notables similitudes tipológicas. Ambos se encuentran a una distancia aproximada de una legua de sus respectivas poblaciones, en entornos rurales de una cierta dificultad de acceso (por la laguna en Villena, a causa de la topografía en Crevillent), pero ubicados en lugares agradables con disponibilidad de manantiales permanentes. Pese a su distinto origen y patronazgo (municipal en el primer caso, señorial en el segundo), las devociones que generan arraigan profundamente en sus contextos locales -tornándose rápidamente identitarias-, y se extienden por las comarcas cercanas. Su fama -que trasciende lo puramente local- se basa en una piedad maravillosista y milagrera que atribuye a los intercesores la capacidad de intervenir -entre otras cosas- sobre las coyunturas climáticas adversas, agravadas durante las pulsaciones climáticas de la Pequeña Edad del Hielo. Obviamente, existen diferencias de categoría: claramente superior en el caso de Villena, como corresponde a una ciudad y a una advocación mariana, que se traduce en la dotación conventual del lugar; en el caso de Crevillent, como población de segundo orden respecto de la capital de su marquesado, la elección de San Cayetano se debió por entero a la señoría.

Como se ha evidenciado, los santuarios son fuente de una amplia y variada conflictividad, dado que en estos lugares piadosos confluyen los derechos -o por mejor decir, los intereses- de diversas jurisdicciones, comunidades o particulares. Las disputas se registran en todos los niveles y entre múltiples actores, pero frecuentemente se originan y encuentran su caldo de cultivo en los enfrentamientos internos entre las facciones de las oligarquías locales.

En primer lugar, los conflictos surgen a propósito del control de los lugares; es decir, por la titularidad del patronato. En el caso de Villena, la amenaza más grave se produjo en el periodo 1575-1593, cuando junto a las intervenciones de los obispos murcianos (reforzados por el Concilio de Trento) podemos intuir la existencia de un grupo de notables opuesto al patronato municipal, o al menos al modo en que se estaba administrando. Con todo, el ayuntamiento defendió siempre, a todo trance, su derecho sobre el lugar,

Crevillent, en 1985 se erigió una nueva parroquia que lleva la denominación del teatino. 
Devociones, conflictividad y clima. Los santuarios de Nuestra Señora de las Virtudes (Villena) y San Cayetano (Crevillent) durante la Edad Moderna

y en la medida en que se consolidó el proceso formativo de la oligarquía local, las amenazas surgidas del frente local nunca volvieron a ser serias ${ }^{211}$. Más aún, el patronato sobre el santuario constituyó una de las principales manifestaciones simbólicas del poder de dicha oligarquía, y por tanto su conservación e incremento quedaba fuera de discusión. Por el contrario, lo sucedido en Crevillent a finales del siglo XVIII y principios del XIX refleja una situación anómala, como corresponde a un periodo de desintegración de las estructuras tradicionales, en una localidad que en todo caso había seguido una evolución muy diferente a la de Villena ${ }^{212}$ : desentendidos los patronos originales y desaparecido un obispo de perfil fuerte -como lo fue Tormo-, un clérigo oportunista se hizo con el control del lugar por la vía -sin duda sorprendente- de la adquisición del terreno. La división entre los grupos de poder locales (evidenciada primero entre el propio clero $^{213}$, y extendida a otras instituciones y «partidos», así como a los estratos populares) determinó el prolongado devenir conflictivo del santuario.

Por lo demás, la defensa del patronato se desplegó en primer término en el terreno de los títulos jurídicos esgrimidos. En el caso de Villena, aunque la ciudad siempre planteó como hecho indiscutible su patronato por título de fundación y dotación, nunca pudo presentar ningún documento que lo acreditara positivamente. Así las cosas, con las normas dictadas por el Tridentino en

211. El estudio de la formación y consolidación de las élites villenenses ha dado recientemente trabajos de gran calidad -ORTUÑo MOLINA, 33 (2006), para el inicio de la Edad Moderna. MOLINA PUCHE, 2005a y 31 (2005b), para el Seiscientos. AzORíN ABELLÁn, 2007, para el Setecientos-. También en Villena el XVII fue el siglo clave en el proceso de oligarquización del municipio castellano (MOLINA PUCHE, 2005a: 447).

212. Prácticamente despoblado con la expulsión morisca de 1609, en las últimas décadas del siglo XVII y la primera mitad del XVIII Crevillent fue escenario de un crecimiento demográfico casi exponencial que entró en crisis a partir de la mitad de la década de 1750, dando lugar a un conjunto de epifenómenos (emigración, bandolerismo, hábitat cavernícola, motines) que caraterizarán a nivel local el final del XVIII y el principio del xIX. A diferencia de Villena, la práctica desaparición de los fondos municipales ha condicionado la ausencia de monografías sobre esta población en la época moderna, vacío solo cubierto por algún trabajo de más amplia óptica (GOZÁLVEZ PÉREZ, 1983) si bien en los últimos tiempos están apareciendo aproximaciones parciales -sobre otros fondos documentales- de gran calidad.

213. No son insólitos los enfrentamientos violentos entre miembros de las órdenes religiosas. Como elemento de comparación, vid. el reciente estudio de CALLADO EsTELA, 39 (2014): 165-187. 
la mano, los obispos murcianos intentaron negarlo; por su parte, los conventuales tendieron a reducirlo a un contenido puramente honorífico. En el caso de San Cayetano, la situación es la inversa: los actos jurídicos que regulaban la cesión de la imagen del santo a la ermita levantada por Ardid resultaban meridianamente claros en sentido negativo, pero aun así fue posible el complicado proceso litigioso y de conflictividad que hemos seguido aquí.

No debe sorprender, por tanto, la frecuente apertura de la vía litigiosa en defensa (o para la consecución) del patronato; pero menos aún el interés que todos los actores ponen en obtener una jurisprudencia favorable y en la consolidación de sus derechos, bien por la vía fáctica (si es preciso, recurriendo a la amenaza e incluso la violencia), bien por la más pacífica de la consuetudo. La larga duración contribuía, por supuesto, a la creación de situaciones de confusión respecto de derechos y obligaciones, como se observa en los sucesos de Villena de 1756-1757; pero no necesariamente tenía que transcurrir un tiempo largo para alcanzar este punto, como se manifiesta en el rápido desencadenamiento del conflicto en el caso de Crevillent.

La mayor parte de estos conflictos terminaron sustanciándose en el Consejo de Castilla. Y en efecto, la actitud de la Corona y de sus tribunales -como no podía ser de otro modo- resultó crucial en el devenir de los acontecimientos. Con la sola excepción de la ocupación del santuario por los agustinos murcianos en 1593 (una victoria episcopal, aunque limitada), Villena -es decir, su oligarquía- disfrutó de un amparo continuo y rápido, hasta el punto de que los títulos jurídicos más fuertes que pudo presentar la ciudad en pro de sus derechos -más allá de unas soñadas y nunca aparecidas bulas papales- no fueron otros que los progresivamente ganados merced a las sucesivas concesiones y reconocimientos reales. De hecho, la continuidad de su patronato no se explica sin este apoyo, como bien sabían sus regidores. Incluso uno de ellos llegó a plantear una suerte de patronato vicario, derivado del regio: en 1592, durante la discusión habida en el seno del consistorio sobre la conveniencia o no de ceder la casa a los agustinos valencianos, Martín Alonso de Medina manifestó que el patronazgo de la casa de Las Virtudes lo tenía la ciudad «en nombre del Rey Nuestro Señor, como patrón que es de las Iglesias de España» ${ }^{214}$; se trataba de una fórmula excesiva, pues

214. AHMV, AACC, 30-I-1592.

Revista de Historia Moderna, n. 35 (2017) (pp. 254-307) | ISSN-e: 1989-9823 | ISSN: 0212-5862 
Devociones, conflictividad y clima. Los santuarios de Nuestra Señora de las Virtudes (Villena) y San Cayetano (Crevillent) durante la Edad Moderna

la Corona nunca alcanzó de iure el reconocimiento del patronato universal sobre todo el territorio peninsular ${ }^{215}$. La misma línea, claramente regalista, pretendió mantener hasta el extremo la Audiencia valenciana en el caso de San Cayetano, al tratar procesalmente las peticiones de amparo presentadas por los Ardid como un recurso de fuerza, e interpretar el conflicto planteado como la defensa de un patronato de legos, dentro de un combate contra el ultramontanismo supuestamente representado por el ordinario diocesano de Orihuela ${ }^{216}$. Sin embargo, cuando el Consejo pudo entrar a ocuparse del asunto, y por mucho que ya se estuviera en el reinado de Fernando VII, no se demoró en cortar una argumentación de tan débil base.

Por supuesto, en el origen de esta conflictividad se encontraban también las disputas por las limosnas y ofrendas. El asunto queda muy claro en el caso crevillentino: las cuantiosas limosnas del santo estuvieron en la base de la demolición de la primera ermita, constituyeron el objetivo básico de los Ardid, y se convirtieron en la primera causa de conflictividad. No debemos, sin embargo, caer en reduccionismos, dada la amalgama de elementos simbólicos de primer orden subyacentes en todo santuario. Pese a la avidez económica de mosén Ardid, no es descartable que sus pretensiones apuntaran más allá, tal vez al logro de una jurisdicción señorial ${ }^{217}$. Al contrario ocurre en el caso

215. La definición del patronato real entonces vigente, contenida en la ley 1, título VI del libro I de la Nueva Recopilación (promulgada por Felipe II en 1565) se refería al patronato sobre las iglesias catedrales y al derecho de presentación de los arzobispados, obispados, prelacías y abadías consistoriales.

216. Llegado el caso, y aunque no hacía el núcleo de la cuestión, la Audiencia invocó -sin demasiada concreción- el antiguo derecho regnícola. Pero sobre todo hizo gala de músculo regalista, espetándole al fiscal eclesiástico que «las opiniones ultramontanas son ya desconocidas» en España, donde únicamente debían servir las leyes del reino y los cánones eclesiásticos admitidos por ellas (AHN, Consejos, 23.187, El cura y clero..., pa. 1. ${ }^{a}$ num. 2. ${ }^{\text {a }: 396 v) . ~}$

217. En su declaración en una prueba testifical solicitada por la parte contraria y practicada en su propia casa el 19-IX-1804, se dice que en el sitio del santuario (que se entendía propiedad de Ardid) existían 15 casas (en realidad, en el entorno próximo se superaban las 25 , más numerosas cuevas, algunas de las cuales aún se conservan). Además, era él mismo quien pagaba «al Excmo. Sr. Conde de Altamira con el pecho que aquellas anualmente hacen» (AHN, Consejos, 23.187, El cura y clero..., pa.1. ${ }^{a}$, num. 2. ${ }^{a}:$ 123, 133-133v). ¿Era la idea última de D. Cayetano Ardid constituir un señorío de jurisdicción alfonsina? Se trata de una suposición plausible que no debe descartarse (vid. Pla Alberola, 12 (1993): 104-124). 
villenense, donde las limosnas nunca constituyeron una fuente saneada de ingresos frente a unos gastos religiosos que durante el siglo XVIII aumentaron muy por encima del resto de las partidas de los propios municipales, dando lugar a continuos problemas de administración ${ }^{218}$. En definitiva, no debería haber existido mucha dificultad en conceptuar el de Villena -de acuerdo con la clasificación establecida por Barrio Gozalo- como un patronato laico comunitario; menos aún, en calificar el de San Cayetano -en su segunda época- dentro de los patronatos puramente eclesiásticos ${ }^{219}$. Sin embargo, el carácter pacífico no parece estar en la naturaleza del patronato. Y una clave importante para entender la conflictividad legal la vuelven a dar las limosnas: el argumento en cuya virtud constituían bienes espirituales fue reiteradamente utilizado (en ambos casos) por la jurisdicción eclesiástica para reclamar sus derechos. Dicho sea de paso, insistiremos en que buena parte de las intervenciones de los ordinarios sobre ambos santuarios las ejecutan mitrados que (tanto Dávila en el siglo XVI como Tormo en el XVIII) se esforzaron por dar aplicación a las disposiciones tridentinas ${ }^{220}$.

Los factores climáticos están presentes en la mayoría de estos conflictos. No puede ser de otro modo, en la medida en que una de las principales funciones asignadas a los intercesores que constituyen el centro de las devociones, es la de poder intervenir sobre una naturaleza frecuentemente incierta y adversa, bien sea ante epidemias y plagas, bien ante la necesidad de lograr unas lluvias que aseguren las cosechas. Dentro de la Pequeña Edad del Hielo, en periodos como el de la «anomalía Maldà», el recurso a las rogativas se intensifica. No obstante, los peculiares mecanismos de estas funciones, que exigen la intervención de distintas instituciones y suponen elevados desembolsos, contienen también el germen de situaciones conflictivas, como hemos tenido ocasión de detallar repetidamente, sin que en todos los casos se verifique una relación directa entre el conflicto y la gravedad de la coyuntura climática. La frecuencia observada en las rogativas a la Virgen de las Virtudes (que en Villena era la máxima intercesora), o las sospechas planteadas - con cierto fundamento-por

218. MORENO NIEVES, 6-7 (1986-1987): 222.

219. BARRIO GOZALO, 2010: 83-88.

220. Entre la abundante bibliografía sobre los conflictos entre la jurisdicción civil y eclesiástica, y a título meramente indicativo, vid. CORTÉS PEÑA, 2006: 437-452. 
los Ardid respecto de las verdaderas intenciones de las que fueron instadas en Crevillent en 1814 y 1815, también dificultan la aplicación de escalas objetivas de intensidad al recurso a las rogativas, y suponen una llamada a la prudencia en el uso de este indicador.

Así pues, hemos pretendido incidir en este trabajo en la importancia y la necesidad de tener en cuenta los contextos locales, tanto en el estudio de la conflictividad relacionada con los santuarios ${ }^{221}$, como incluso en la valoración de determinados proxy-data climáticos. Ciertamente, podemos encontrar situaciones similares en otras muchas poblaciones ${ }^{222}$, cosa que evidencia su conexión con las coyunturas generales. Pero resulta fundamental prestar atención a los escenarios particulares. Valga esto también para el último -e importante- factor a tener en cuenta: nos referimos al amplio mundo de las respuestas populares, las de campesinos y jornaleros, verdaderos sufridores de las coyunturas naturales adversas. Temidos por las autoridades locales y episcopales ${ }^{223}$, en ocasiones movidos por su propia inercia -más o menos espontánea, más o menos organizada ${ }^{224}$-, quizá en no pocas ocasiones manejados desde las redes de clientelismo que también se insinúan en los casos estudiados, pero -en todo caso- siempre presentes y vigilantes respecto de unos centros espirituales a los que se sentían profundamente vinculados, hasta el punto (baste pensar en lo sucedido en Crevillent durante el Trienio LIberal) de considerarlos como propios. Y es que las creaciones de las élites, a fuer de su éxito, también podían terminar volviéndose contra sus creadores.

221. Resulta del todo pertinente la llamada a «encajar los conflictos en el eje de lo cotidiano» recientemente efectuada por IGLESIAS RODRÍGUEZ, 2016: 333.

222. Valgan como ejemplo los litigios de finales de la década de 1760 y principios de 1770 en torno a la devoción de la Virgen de la Piedad de Baza estudiados por CORTÉs PEÑA, 1 (1993): 331-347.

223. PEÑA DíAZ, LXXIV, 248 (2014).

224. Crevillent había conocido graves motines en 1756 y -sobre todo- 1766. En este último, uno de los cabecillas será el primer gran bandolero social que dio el pueblo: Manuel Manchón, «el català». En 1816, en los argumentos aducidos por el clero local para no mantener la imagen de San Cayetano en la ermita de la sierra, se decía que «entre el año» el lugar era «una acogida de foragidos» (AHN, Consejos, 23.187, El cura y clero..., pa. 4. a.: 84v.). Es evidente que los Ardid debieron mantener algún tipo de relación con las nutridas partidas de bandoleros - como la de Jaime el Barbudoque se enseñorearon de la zona, en particular durante el Trienio Liberal, y que estos no debieron permanecer ajenos a la situación. 
Devociones, conflictividad y clima. Los santuarios de Nuestra Señora de las Virtudes (Villena) y San Cayetano (Crevillent) durante la Edad Moderna

\section{Bibliografía}

Alberola Romá, Armando, Los cambios climáticos. La Pequeña Edad del Hielo en España, Madrid, Cátedra, 2014.

Alberola RomÁ, Armando, Bueno Vergara, Eduardo y García Torres, Adrián, «Sequías y rogativas en tierras meridionales valencianas durante el siglo XVIII», en Luis Alberto Arrioja Díaz Viruell y Armando Alberola Romá (eds.), Clima, desastres y convulsiones sociales en España e Iberoamérica. Siglos XVII-XX, Alicante, Universidad de Alicante-El Colegio de Michoacán, 2016: 123-155. AMORós, León, El monasterio de Santa Clara de Gandía y la familia ducal de los Borja, Gandía [s.n.], 1981.

Atienza López, Ángela, Tiempos de conventos, Madrid, Marcial Pons Historia, Universidad de la Rioja, 2008.

AZORín ABEllán, José, Las «familias poderosas» de la ciudad de Villena en el Antiguo Régimen. Análisis del ascenso, formación y consolidación de un grupo de poder, Alicante, Instituto Alicantino de Cultura «Juan Gil-Albert», 2007.

BARRIENDOS, Mariano y LLASAT, Carmen, «The case of the 'Maldà' Anomaly in the western mediterranean basin (1760-1800): an example of a strong climatic variability», Climatic Change, 61/1-2 (2003): 191-216. https://doi. org/10.1023/A:1026327613698

Barrio Gozalo, Maximiliano, El clero en la España moderna, Córdoba, Caja Sur, CSIC, 2010.

BENÍTEZ SÁNCHEZ-BLANCO, Rafael, «Arbitrio del Dr. Mancebón para la reforma de la ermita de Nuestra Señora de las Virtudes de Villena y creación de un colegio para niños moriscos (1587-88)», en Homenatge al doctor Sebastià García Martínez, València, Conselleria de Cultura, Educació i Ciència/Universitat de València, 1988: I, 287-300.

Bueno Vergara, Eduardo, Clima y medicina en el Alicante de siglo XVIII. Amenazas medioambientales, vulnerabilidad social y estrategias de resistencia, Tesis doctoral, Universidad de Alicante: 2014. Disponible en http://rua.ua.es/dspace/ handle/10045/44521 [consultada el 15 de marzo de 2017].

Callado Estela, Emilio, «Desórdenes en la Provincia franciscana de Valencia a finales del siglo XVII», Cuadernos de Historia Moderna, 39 (2014): 165-187. Disponible en: http://revistas.ucm.es/index.php/CHMO/article/view/45846

CANDElas Orgilés, Ramón, Las ermitas de la provincia de Alicante, Alicante, Diputación de Alicante, 2004. 
Devociones, conflictividad y clima. Los santuarios de Nuestra Señora de las Virtudes (Villena) y San Cayetano (Crevillent) durante la Edad Moderna

CORTÉS PEÑA, Antonio Luis, «Religiosidad popular y conflicto: un ejemplo bastetano», Hespérides: Anuario de investigaciones, 1 (1993): 331-347.

CORTÉS PeÑA, Antonio Luis, «Conflictos jurisdiccionales entre la iglesia y los poderes civiles en el siglo XVIII», en Antonio L. Cortés Peña (ed.), Poder civil, iglesia y sociedad en la Edad Moderna, Granada, Universidad de Granada, 2006: 437-452.

Creus Novau, José y SAz SÁnChez, Miguel A., «Las precipitaciones de la época cálida en el sur de la provincia de Alicante desde 1550 a 1915», Revista de Historia Moderna. Anales de la Universidad de Alicante, 23 (2005): 35-48. https://doi.org/10.14198/RHM2005.23.02

Cutillas Bernal, Enrique, El patronato de la ciudad de Alicante sobre el monasterio de la Santa Verónica en la huerta de la ciudad (1518-1804), Tesis doctoral, Alicante, Universidad de Alicante, 1995. Disponible en http://rua.ua.es/ dspace/handle/10045/5464 [consultada el 25 de marzo de 2017].

DIFERENTES INSTRUMENTOS, letras executoriales, y otros documentos pertenecientes a el Patronato de la Santíssima Imagen de N. Señora de las Virtudes, y Monasterio de Padres Agustinos Calzados [s.l.], Ayuntamiento de Villena, 1768. Citado como Diferentes instrumentos... [1768].

DOMENE Verdú, José Fernando, «El convento de la Virgen de las Virtudes de Villena y los frailes agustinos en el siglo XVI», Revista del Vinalopó, 14 (2011): 215-333.

García, P. Fr. Mateo, Prothocolo, y libro de la hazienda que tiene este convento de Nuestra Señora de las Virtudes, Orden de Nuestro Padre San Augustín, en censos, tierras y casas, en Villena, Yecla, y Sax (manuscrito AHMV, 9/16, 1722).

García LujÁn, Máximo, Historia del santuario de Nuestra Señora de las Virtudes, Villena, Asociación Nuestra Señora de las Virtudes/Ayuntamiento de Villena, 1988.

García LujÁn, Máximo y GalBis, José, «Los agustinos en Villena (Alicante)», Archivo Agustiniano, 96/214 (2012): 73-122.

GARCÍA TORRES, Adrián, Riesgo natural, extremismo climático y desastre en tierras meridionales valencianas durante el siglo XVIII, Tesis doctoral, Universidad de Alicante, 2015. Disponible en http://hdl.handle.net/10045/50214 [consultada el 15 de marzo de 2017].

GARCÍA TORRES, Adrián, «Sequías y riadas durante la anomalía Maldà en la fachada mediterránea española: una aproximación al territorio sur alicantino, 17601800», en Luis Alberto Arrioja Díaz Viruell y Armando Alberola Romá (eds.), 
Devociones, conflictividad y clima. Los santuarios de Nuestra Señora de las Virtudes (Villena) y San Cayetano (Crevillent) durante la Edad Moderna

Clima, desastres y convulsiones sociales en España e Iberoamérica. Siglos XVII-XX, Alicante, Universidad de Alicante-El Colegio de Michoacán, 2016: 157-178. GIMÉNEZ LÓPEZ, Enrique, «La Santa Faz y Alicante: peregrinaje por cinco siglos de Fe», en Ayuntamiento de Alicante, Santa Faz. V Centenario, Comisión V Centenario, Alicante, Ayuntamiento de Alicante, 1989: 34-39.

GozÁlvez PÉrez, Vicente, Crevillente. Estudio urbano, demográfico e industrial, Alicante, Universidad de Alicante/Ayuntamiento de Crevillente, 1983.

HenARES DíAZ, Francisco, «Villena: los franciscanos descalzos en la Edad Moderna», en Inocencio Galindo Mateo, Sancho García de Medina y el arcedianato de Villena. Política, fe y cultura en torno al Renacimiento levantino, Villena, Ayuntamiento de Villena, 2011: 203-221.

IGLESIAS RODRÍGUEZ, Juan José, "Conflictos y violencias en las fronteras de lo cotidiano. Hacia una tipología de las transgresiones en la Edad Moderna», en José Luis Betrán, Bernat Hernández y Doris Moreno (eds.), Identidades y fronteras culturales en el mundo ibérico de la Edad Moderna, Bellaterra, Universidad Autònoma de Barcelona, 2016: 333-348. Disponible en: https://idus.us.es/ xmlui/handle/11441/55227

IRIGOYen, Antonio y GARCíA HourCADE, José Jesús, «Aplicaciones Tridentinas: la Visita del obispo Sancho Dávila al cabildo de la catedral de Murcia», Investigaciones históricas: época moderna y contemporánea, 22 (2002): 11-22. Disponible en: http://uvadoc.uva.es/handle/10324/17837

LóPez de Ayala, Ignacio (trad.), El Sacrosanto y ecuménico Concilio de Trento, Barcelona, Imp. B. Espona, 1845.

MARTÍNEZ ESPAÑOL, Gonzalo, «Incendio en la sierra de Crevillente y en la ermita de San Cayetano en 1712», Crevillente. Semana Santa, 77 (2014): 254-259.

Mas Galvañ, Cayetano, "El motín de Esquilache en Crevillent», Separata Crevillente. Semana Santa (2003): 1-13.

MAS GALVAÑ, Cayetano, «La gestión de la catástrofe. Acción estatal y lucha contra la plaga de langosta en las diócesis de Murcia y Orihuela (1756-1758)», Relaciones. Estudios de Historia y Sociedad, 129 (2012): 51-86. Disponible en: http://rua.ua.es/dspace/handle/10045/35186

MAS MAS, Francisco «Datos históricos de la Religión en Crevillente», Crevillente. Semana Santa, 2 (1936): 11-12.

Molina PuCHE, Sebastián, Familia, poder y territorio. Las elites locales del corregimiento de Chinchilla-Villena en el siglo XVII, Tesis doctoral, Universidad de 
Murcia, 2005a. Disponible en https://digitum.um.es/xmlui/handle/10201/183 [consultada el 25 de marzo de 2017].

Molina PuCHE, Sebastián, «Élite local: análisis de un concepto a través de las familias de poder del corregimiento de Villena-Chinchilla en el siglo XVII», Estudis. Revista de Historia Moderna, 31 (2005b): 197-222. Disponible en: https://www.uv.es/dep235/PUBLICACIONS_IV/PDF9.pdf

Montesinos, José, Compendio histórico oriolano (manuscrito propiedad de la Caja Rural Central de Orihuela, vol. 15, ca. 1795, con anotaciones hasta 1810).

Moreno Nieves, José Antonio, «Estudio de la hacienda municipal a través de los libros de propios de la ciudad de Villena (1708-1766)». Revista de historia moderna. Anales de la Universidad de Alicante, 6-7 (1986-1987): 207-229. http://dx.doi.org/10.14198/RHM1986-1987.6-7.11

ORTuÑo Molina, Jorge, La incorporación del Marquesado de Villena a la Corona de Castilla en el reinado de los Reyes Católicos, Tesis doctoral, Universidad de Murcia, Murcia, 2003.

ORTUÑO MOLINA, Jorge, «Poder real absoluto. Oligarquías y transformaciones del paisaje agrario en el marquesado de Villena a finales de la Edad Media», Historia. Instituciones. Documentos, 33 (2006): 487-512

PEÑa DíAz, Manuel, «Tolerar la costumbre: Ferias y romerías en el siglo XVIII», Hispania, LXXIV, 248 (2014): 777-806. http://dx.doi.org/10.3989/ hispania.2014.023

Pla Alberola, Primitivo J. «La jurisdicción alfonsina como aliciente para la recolonización del territorio», Revista de Historia Moderna. Anales de la Universidad de Alicante, 12 (1993): 79-140. http://dx.doi.org/10.14198/RHM1993.12.02 Soler García, José María, La relación de Villena de 1575, Alicante, Instituto de Estudios Alicantinos/Diputación Provincial de Alicante, 1974.

SOler García, José María, Historia de Villena desde la prehistoria hasta el siglo XVIII, Madrid, Ayuntamiento de Villena/Fundación Municipal José María Soler, 2009.

VILAR, Juan Bautista, «Un proyecto de colegio-residencia de la Compañía de Jesús en la ciudad de Villena en 1701», en Historia y Humanismo: homenaje al prof. Pedro Rojas Ferrer, Murcia, Universidad de Murcia, 2000: 475-491. 